\title{
Design, Formulation and in vivo Evaluation of Novel Honokiol-Loaded PEGylated PLGA Nanocapsules for Treatment of Breast Cancer
}

This article was published in the following Dove Press journal: International Journal of Nanomedicine

\author{
Yusuf A Haggag (1) \\ Rowida R lbrahim (iD) ${ }^{2}$ \\ Amin A Hafiz ${ }^{3}$ \\ 'Department of Pharmaceutical \\ Technology, Faculty of Pharmacy, Tanta \\ University, Tanta, Egypt; ${ }^{2}$ Medical \\ Biochemistry and Molecular Biology \\ Department, Faculty of Medicine, Tanta \\ University, Tanta, Egypt; ${ }^{3}$ Department of \\ Clinical Nutrition, Faculty of Applied \\ Medical Sciences, Umm Al-Qura \\ University, Mecca, Kingdom of Saudi \\ Arabia
}

Background: Honokiol $(\mathrm{HK})$ is a common herbal medicine extracted from magnolia plants. Low aqueous solubility and limited bioavailability of HK have hindered its clinical application, especially for cancer treatment. Nano-drug delivery system has the potential to enhance HK delivery and therefore, enhance its anti-cancer activity.

Purpose: The study's aim is to design novel PEGylated-PLGA polymeric nanocapsules (NCs) for HK delivery to breast tumor-bearing mice after systemic administration.

Methods: Formulation of different HK-loaded NCs and their physio-chemical characterization were optimized through the use of different formulation variables. The antitumor activity of the HK-loaded NCs was investigated both in vitro using MCF-7 and EAC breast cancer cell lines and in vivo using solid Ehrlich carcinoma (SEC) breast cancer model.

Results: The optimum HK-loaded NCs were prepared from 15\% PEG-PLGA diblock copolymer and exhibited the lowest nano size of $125 \mathrm{~nm}$, smooth spherical morphology, highest drug loading of $94 \%$ and highest cellular uptake into breast cancer cells. HK-loaded PEGylated NCs can effectively inhibit the in vitro cell growth of breast cancer cells by $80.2 \%$ and $58.1 \%$ compared to $35 \%$ and $31 \%$ with free $\mathrm{HK}$ in the case of MCF-7 and EAC, respectively. HK-loaded NCs inhibited SEC tumor growth by 2.3 fold significantly higher than free HK, in vivo.

Conclusion: The designed drug delivery system encapsulating HK exhibited a pronounced decrease in tumor growth biomarkers meanwhile proved its safety in animals. Therefore, $15 \%$ PEGylated HK-loaded NCs may act as a promising new approach for breast cancer treatment.

Keywords: honokiol, nanocapsule, PEG-PLGA copolymers, formulation variables, anticancer activity, solid Ehrlich carcinoma, breast cancer

\section{Introduction}

Breast cancer is the most common type of cancer and the second leading reason for cancer-related mortality in females. Recently, American Cancer Society annual estimates for breast cancer showed that approximately 268,600 new cases of invasive breast cancer, 62,930 of early breast cancer new cases will be diagnosed in American women and about 41,760 females will die from breast cancer during this year. Despite major advances in screening programs and treatment protocols, one from every eight women will develop breast cancer. ${ }^{1}$ Therefore, more-effective therapeutic approaches are critically needed to decrease morbidity and to combat breast cancer. ${ }^{2}$
Correspondence: Yusuf A Haggag Department of Pharmaceutical

Technology, Faculty of Pharmacy, Tanta

University, Tanta 3IIII, Egypt

Tel +2 0I220I046I2

Fax +2 0403335466

Email youssif.hagag@pharm.tanta.edu.eg
International Journal of Nanomedicine 2020:15 1625-1642

1625 
Honokiol is a bioactive polyphenol extracted from Magnolia species which has been commonly used in China and Japan as an herbal medicine. ${ }^{3}$ It is well known for its wide pharmacological activity as it possesses anti-cancer, anti-viral, anti-inflammatory, antioxidant, antithrombotic and neurological effect. ${ }^{3-7}$ Besides, HK is considered as a natural peroxisome proliferator-activated receptor gamma (PPAR $\gamma$ ) agonist that can be used clinically to control hyperglycemia and its unfavorable side effects, such as weight gain. ${ }^{8}$ Although honokiol can be used for the treatment of all previous diseases, its poor aqueous solubility is the major hurdle against its therapeutic applicability. Therefore, it is essential to design a proper drug delivery system to improve HK solubility and hence its bioavailability and therapeutic efficacy.

Nanotechnology has achieved major progress in the design, synthesis, and development, of different forms of nanosystems to fulfill different drug purposeful applications. Polymeric nanoparticles as a type of colloidal dispersions have been studied for the delivery of bioactive drugs either in pharmaceutical or biotechnological field. ${ }^{9-12}$ Among the different polymeric nanoparticles used, nanocapsules have attracted increased attention. ${ }^{13,14}$ Their advantages over classical drug delivery systems are numerous, as they can enhance the aqueous solubility of lipophilic drugs, control its release and increase the bioavailability of different drugs. ${ }^{14-16}$ In addition, nanocapsule-base drug delivery systems were effectively used in cancer treatment due to its biodegradability, high drug-loading capacity, high cellular uptake, preferable intra-tumor bio-distribution and possible functionalization for cancer targeting. ${ }^{14}$

Polymeric nanocapsule encapsulating lipophilic drugs generally consists of polymeric shell and an oily core containing dissolved drug. Therefore, the use of appropriate biodegradable and biocompatible polymers like poly (lactide-co-glycolide) (PLGA), polylactic acid (PLA) and poly ( $\varepsilon$-caprolactone) (PCL) is commonly adopted in formulation of NCs. ${ }^{13}$ PEGylated PLGA and PCL diblock copolymers have emerged as a fascinating class of drug delivery polymers for biomedical and drug delivery applications. ${ }^{17-19}$ These polymers are sufficiently stable in vitro and longcirculating in vivo besides they showed high cancer cell internalization by Enhanced Penetration Retention (EPR) effect to achieve passive targeting to tumor site. ${ }^{12,20}$

Several attempts are described to develop different carriermediated drug delivery strategies for HK based on nanotechnology. These nano-drug delivery systems include nanosuspension, ${ }^{21}$ nanoparticles, ${ }^{22-24}$ microbubbles, ${ }^{25}$ liposomes $^{26}$ and polymeric micelles. ${ }^{27,28}$ Recently, very few studies tried quantum dotsbased nanocapsules for co-delivery of honokiol and other anticancer drugs for theranostic applications. ${ }^{29,30}$

This is the first paper to report the formulation of PEGylated PLGA NCs encapsulating honokiol. To our knowledge, no studies so far have investigated the anticancer potential of HK-loaded PEGylated PLGA NCs for treatment of the Solid Ehrlich Carcinoma breast cancer model in vivo after systemic administration.

The objective of this study is to design biocompatible HK-loaded PEGylated PLGA NCs for breast cancer treatment. The first aim was to adjust various formulation parameters, such as the PEG content in the polymeric backbone and the type of the oily core, in order to optimize the physio-chemical properties of HK-loaded NCs. The second aim was to investigate cellular delivery and in vitro cytotoxicity of HK NCs using two different breast cancer cell lines of MCF-7 and EAC. The last aim is to study the anti-tumor activity and safety profile of optimum HK-loaded NC in vivo using the SEC breast cancer model.

\section{Materials and Methods Materials and Reagents}

PEG-PLGA diblock copolymers (Resomer ${ }^{\circledR}$ RGP d 50155 (15\% PEG of MW $5 \mathrm{kDa}))$ Resomer $^{\circledR}$ RGP d $50105(10 \%$ of PEG, MW $5 \mathrm{kDa}$ ) and Resomer ${ }^{\circledR}$ RGP d 5055 (5\% PEG of MW $5 \mathrm{kDa}$ ) were purchased from Boehringer Ingelheim Ltd. (Ingelheim, Germany). Honokiol, coumarin 6, dialysis tubing (MWCO $2000 \mathrm{Da}$ ), SP-Sephadex C-25 resin, almond oil, castor oil, isopropyl myristate, soybean lecithin, tween 80, acetone, absolute ethanol (ultra-pure grades) were purchased from Sigma Chemical Co. (St. Louis, USA). Dulbecco's modified Eagle's medium (DMEM) media, trypsin/EDTA, phosphate-buffered saline (PBS), fetal bovine serum (FBS), and penicillin/streptomycin were obtained from Gibco, Invitrogen, UK.

MCF-7 breast cancer cell line was obtained from the Cell Culture Department, VACSERA (Cairo, Egypt). Cells were routinely grown in T75 canted-neck tissue culture flasks. Cells were cultured in low glucose DMEM media supplemented with FBS $(10 \% \mathrm{v} / \mathrm{v})$, L-glutamine $\left(2 \mathrm{mmol} \mathrm{L}^{-1}\right)$, penicillin $\left(100 \mathrm{U} \mathrm{mL}^{-1}\right)$ and streptomycin $\left(100 \mu \mathrm{g} \mathrm{mL}^{-1}\right)$. Medium renewal was done every three days at $80 \%$ confluence. Cell cultures were incubated at conditions of $5 \% \mathrm{CO}_{2}$ and $37^{\circ} \mathrm{C}$. Ehrlich Ascites Carcinoma cell line (EAC) was obtained from Experimental Oncology Unit of the National Cancer Institute (NCI) (Cairo University, Cairo, Egypt) was 
maintained by weekly intraperitoneal transplantation of respective tumor cells $\left(2 \times 10^{6}\right.$ cells per mouse $)$ in stock animals.

\section{Preparation of HK-Loaded Polymeric NCs}

\section{Screening Solubility of HK in Different Oils}

The practical solubility of HK in different oils used for NCs preparation (almond oil, castor oil, or isopropyl myristate) was determined by the shake-flask saturation method. ${ }^{14}$ Excess amount of $\mathrm{HK}(5 \mathrm{mg})$ was placed in glass vials containing $1 \mathrm{~mL}$ of the (almond oil, castor oil, or isopropyl myristate), sealed and shaken at $100 \mathrm{rpm}$ for two days at $37^{\circ} \mathrm{C}$. After centrifugation, an aliquot from the supernatant was withdrawn and mixed with acetone and ethanol mixture $(1: 1 \mathrm{v} / \mathrm{v})$. The solubility of HK in different oils was determined by using a UV spectrophotometer (Model UV-1601 PC; Shimadzu, Kyoto, Japan) and measuring the absorbance at $294 \mathrm{~nm}^{24}$ The amount of soluble HK was estimated according to relevant standard plots. Standard plots were obtained after testing the solubility of five different concentrations of $\operatorname{HK}(0.1,0.2,0.4,0.6$ and $0.8 \mathrm{mg} / \mathrm{mL}$ ) in each oil type separately. Each HK concentration was treated as previously mentioned and the UV absorbance was measured. A linear relationship was plotted between absorbance and HK concentration.

\section{Formulation of HK-Loaded NCs}

HK-loaded NCs were prepared by the nanoprecipitation method as described by ${ }^{31}$ with some modifications. The oily phase composed of $50 \mathrm{mg}$ of polymer (5\% PEGPLGA, $10 \%$ PEG-PLGA or 15\% PEG-PLGA diblock copolymers), $5 \mathrm{mg}$ of $\mathrm{HK}, 25 \mathrm{mg}$ of soybean lecithin and $500 \mu \mathrm{L}$ of oil (almond oil, castor oil, or isopropyl myristate) dissolved in $5 \mathrm{~mL}$ of acetone/ethanol $(1: 1 \mathrm{v} / \mathrm{v})$ mixture. This oily phase was added dropwise into $10 \mathrm{~mL}$ of aqueous phase containing $0.2 \%$ of Tween 80 . The final mixture was kept under magnetic stirring for $60 \mathrm{~min}$ to facilitate organic solvent diffusion and formation of NCs. Elimination of organic solvents was done using a rotary evaporator under reduced pressure then lyophilized using Freeze-dryer (Crydos-50, Telstar, Spain). Coumarin 6 labeled NCs were prepared according to the previous steps with only one modification by adding coumarin 6 $(100 \mu \mathrm{g})$ to the oily phase. Fluorescent HK-loaded NCs were also evaluated with respect to, particle size, polydispersity index (PDI) and zeta potential. Process variables, such as PEG content in the polymeric backbone and type of the oily core are listed in Table 1, with the identifying code for each HK-loaded NC formulation.

\section{Physicochemical Characterization of HK-Loaded NCs}

The mean particle size and particle size distribution of HK-loaded NCs were determined depending on the Dynamic Light Scattering technique (Zetasizer 5000, Malvern Instruments, Malvern, UK). HK-loaded NCs suspension was prepared by dispersing lyophilized-powder into ultrapure water, a liquid sample was further diluted and the average of three measurements was recorded. Another aliquot of colloidal suspensions was diluted in aqueous $0.001 \mathrm{M} \mathrm{KCl}$ solutions to adjust the sample conductivity, and Laser Doppler Anemometry (Zetasizer 5000, Malvern Instruments, Malvern, UK) was used to measure the zeta potential of HK-loaded NCs. NP surface morphology was studied using Transmission Electron Microscopy (JOEL JEM 2000 EX200) operating at an accelerating voltage of $80 \mathrm{kV}$. Liquid samples were placed on a formvar-coated grid with evaporated carbon for drying before scanning.

\section{Determination of HK Encapsulation Efficiency (\%E.E)}

The encapsulation efficiency (\%E.E) of HK-loaded NCs was determined by the indirect method. Firstly, the purification of $\mathrm{NC}$ samples to remove the un-entrapped drug was done by using a PD10 desalting column (GE Healthcare) with Tris buffer and purified fractions were collected. Secondly, the amount of non-encapsulated HK in the supernatant after purification of NCs suspension was determined by high-performance liquid chromatography technique (HPLC) according to the previously reported

Table I Process Variables for HK-Loaded NCs and Corresponding Identifiers

\begin{tabular}{|l|l|l|}
\hline Formulation Identifier & Polymer Type & Oily Core \\
\hline FI & $5 \%$ PEG-PLGA & Almond oil \\
F2 & $5 \%$ PEG-PLGA & Castor oil \\
F3 & $5 \%$ PEG-PLGA & Isopropyl myristate \\
F4 & $10 \%$ PEG-PLGA & Almond oil \\
F5 & $10 \%$ PEG-PLGA & Castor oil \\
F6 & $10 \%$ PEG-PLGA & Isopropyl myristate \\
F7 & $15 \%$ PEG-PLGA & Almond oil \\
F8 & $15 \%$ PEG-PLGA & Castor oil \\
F9 & $15 \%$ PEG-PLGA & Isopropyl myristate \\
\hline
\end{tabular}


method. ${ }^{24} 100 \mu \mathrm{L}$ of the NCs preparations were diluted by the mobile phase. The amount of free HK was analyzed using HPLC equipment (Waters ${ }^{\circledR} \mathrm{C} 18-5$ column mm, 5 $\mu \mathrm{m})$. The composition of the mobile phase was methanol, acetonitrile, and water $(55: 20: 25, \mathrm{v} / \mathrm{v} / \mathrm{v})$ at a flow rate of $1 \mathrm{~mL} \min ^{-1}$. The injection volume was $40 \mu \mathrm{L}$ and the wavelength for UV detection was $294 \mathrm{~nm}$.

\section{In vitro Release Profile}

A sample of HK-loaded $\mathrm{NC}$ formulation containing a predetermined amount of $\mathrm{HK}$ was placed into a $10 \mathrm{kDa}$ dialysis bag. The dialysis membrane containing HKloaded NCs was agitated at $100 \mathrm{rpm}$ in a receptor media composed of $50 \mathrm{~mL}$ PBS (pH 7.4) containing tween 80 $(1 \% \mathrm{w} / \mathrm{v})$ at $37^{\circ} \mathrm{C}$. At predetermined time interval points, $1 \mathrm{~mL}$ sample was withdrawn and replaced by an equal fresh volume of the same media at $37^{\circ} \mathrm{C}$ to maintain sink conditions. ${ }^{14}$ The same amount of HK was dissolved in DMSO and placed into the same dialysis bag for release comparison. This control experiment was set up to ensure the presence of sink conditions and the absence of nonspecific adsorption of HK to the dialysis membrane. HK concentration was assessed by HPLC method as previously reported. ${ }^{24}$

\section{In vitro Stability}

HK-loaded $\mathrm{NC}$ preparations were sealed in glass vials and stored in the desiccator at room temperature of $25^{\circ} \mathrm{C}$. The stability of HK-loaded NC lyophilized-powders (F1, F4, and F7) was tested every time intervals of $0,2,4$ and 6 months after preparation to determine the sample size, PDI, zeta-potential and \% E.E of NC formulations. Each sample was tested three times and the average of three different measurements was presented.

\section{Seeding of MCF-7 and EAC Cancer Cell Lines}

MCF-7 human breast cancer cells were harvested, when they are $90 \%$ confluent, and the cell suspension was centrifuged at $1200 \mathrm{rpm}\left(4^{\circ} \mathrm{C}\right)$ for 5 mins for cell precipitation. The cell pellets were resuspended in DMEM complete growth medium. EAC cells were obtained from the ascites fluid of $\mathrm{BALB} / \mathrm{C}$ mice bearing $8-10$ days induced ascites tumor. EAC was suspended in PBS before treatment. Cell count was performed on a $10 \mu \mathrm{L}$ cell sample using a Neuberger hemocytometer.

\section{Cellular Uptake of HK-Loaded NCs}

Cellular uptake of coumarin 6-tagged HK-loaded NCs (F1, F4, and F7) into MCF-7 cell line was evaluated using flow cytometry and confocal laser scanning microscopy. ${ }^{11,13}$ Briefly, for flow cytometry analysis, treatment with either coumarin 6 solutions or coumarin 6 labeled HK NCs was suspended in Optimem ${ }^{\circledR}$ media and added to MCF-7 cells for $24 \mathrm{hrs}$ in 6-well plates. Cells were collected by trypsinization then treated with FACS buffer. Cellular uptake of HK-loaded NCs was quantified by gating cells for positive coumarin 6 fluorescence and results were analyzed using BD FACS Calibur flow cytometer (BD Biosciences). Three independent experiments were used for measurements and cellular uptake values were calculated as mean \pm SD. Cellular localization of Coumarin 6-tagged HK-loaded NCs was evaluated qualitatively by confocal laser microscope (Carl-ZEISS Cell Observer, Confocal Microscope, LSM-710, Germany). Coumarin 6-tagged HK-loaded NCs fluorescence was observed by using a 456-nm excitation filter and emission wavelength of $(\lambda \mathrm{Em}=500 \mathrm{~nm})$. Intracellular localization of fluorescent NCs into MCF-7 cells was detected one day after treatment. Briefly, MCF-7 cells were seeded into a 6-well plate, containing two fixed coverslips incubated into $2.0 \mathrm{~mL}$ of DMEM growth medium. Coverslips were mounted using mounting media and counterstained with DAPI. Cellular localization of labeled NCs was represented by the green fluorescence, while cell nuclei were demonstrated by blue fluorescence signals. Untreated MCF-7 cells and cells treated with free coumarin 6 were included as negative and positive controls, respectively.

\section{In vitro Cell Viability Assay}

MCF-7 breast cancer cell line was seeded in 24-well plates and incubated with $0.5 \mathrm{~mL}$ of complete growth media. After $24 \mathrm{~h}$, cells were treated with blank NCs, free HK or HK-loaded NCs (F7) with different concentrations (5, $10,20 \mu \mathrm{M})$. Cytotoxicity was examined by MTT assay as previously reported by. ${ }^{11,20}$ After treatment with 24, 48 and $72 \mathrm{~h}$, media was removed and cells were treated by $500 \mu \mathrm{L}$ of $(15 \% \mathrm{v} / \mathrm{v}$ MTT solution). MCF-7 cells were incubated at $37^{\circ} \mathrm{C}$ and $5 \% \mathrm{CO}_{2}$ for $3 \mathrm{~h}$. Afterward, formazan crystals formed were dissolved in DMSO $(500 \mu \mathrm{L})$ and the plate was read at $570 \mathrm{~nm}$ in an FLUO star Omega microplate reader (BMG Labtech) and the results were expressed as the cell viability after treatment was compared to control cell viability. The viability of EAC cells 
after treatment with different concentrations of free $\mathrm{HK}$ and HK-loaded NCs (F7) $(5,10,20 \mu \mathrm{M})$ was tested by trypan blue exclusion assay as previously reported by. ${ }^{32,33}$ Briefly, $2.5 \times 10^{5} \mathrm{cell} / \mathrm{mL}$ of EAC cells was resuspended in PBS and incubated for $3 \mathrm{~h}$ at $37^{\circ} \mathrm{C}$. At the end of the incubation period, an equal volume of trypan blue dye solution was added to cell samples, and afterward, the unstained alive cells and stained dead cells were counted using a hemocytometer. The percent of cell viability for each test was calculated.

\section{In vivo Study}

\section{Animals}

Thirty-two female Swiss albino mice (18-20 g) were fed water and standard pellet chow (EL-Nasr Chemical Company, Cairo, Egypt) ad libitum for the whole duration of the in vivo experiment. The in vivo study was performed in accordance with the guide of the National Institutes of Health about the use and care of laboratory animals (NIH Publications No. 8023, revised 1978) and approved by Tanta University Animal Ethical Committee, Egypt. Mice were housed and allowed to acclimatize to laboratory conditions for 7 days prior to the experiment. The cell viability of EAC cells aspirated from the mice peritoneal cavity was adjusted to be $98 \%$ as calculated from the trypan blue exclusion assay. A xenograft model of Solid Ehrlich Carcinoma (SEC) was induced in female Swiss albino mice by subcutaneous implanting of $2 \times 10^{6}$ viable EAC cells suspended in $200 \mu \mathrm{L}$ of saline in the right thigh of each mouse. The tumor developed as a palpable solid tumor mass which was achieved within 12 days postimplantation in all mice..$^{12,20}$

\section{In vivo Anti-Tumor Activity}

The antitumor activity of HK-loaded $\mathrm{NC}$ was evaluated in vivo using mice, bearing a solid tumor of mammary origin. Mice rendered tumor-bearing were divided randomly into 4 groups, each containing 8 animals. Animals served as the control group received saline as an intraperitoneal injection. A volume of $0.2 \mathrm{~mL}$ of HK-NCs suspension was injected into the lower right quadrant of mice abdomen using $25 \mathrm{~g}$ needle gauge after disinfection of the abdominal area with alcohol. The first treated group was given blank NCs and the second treated group was given an intraperitoneal administration of frees $\mathrm{HK}$ at a dose of $15 \mathrm{mg} \mathrm{kg}^{-1}$. The last treated group was injected by HKloaded NP (F7) at the same dose. All treatments were injected every three days with a total of 5 injections during the whole experiment. The treatment protocol for all groups was started on day 13 and extended to the 30thday post-implantation. Tumor volumes were recorded from the start point of the treatment and thereafter every 2 days till the last measurement taken at the 17th day of treatment and just prior to the sacrifice of surviving animals. A digital Vernier caliper was used to record dimensions $(\mathrm{mm})$ and the following formula was applied to calculate the volume of the developed tumor mass; ${ }^{34}$

Tumor volume $\left(\mathrm{mm}^{3}\right)=0.52$.length.width ${ }^{2}$

Drug efficacy was calculated by the percentage of tumor growth inhibition as previously reported by. ${ }^{35}$ After finishing the experiment, all animals were sacrificed after being anesthetized with ether and blood was withdrawn into a complete dry sterile centrifugation tubes, left to clot at room temperature for $30 \mathrm{~min}$, centrifuged $(1000 \mathrm{~g})$ for 20 $\min$ at $4^{\circ} \mathrm{C}$. Serum was separated, collected and stored at $-20^{\circ} \mathrm{C}$ for further biochemical analysis. Implanted tumors were excised to be weighed. The changes in tumor weights for each animal group were recorded.

\section{ELISA Assay for Tumor Growth Biomarkers}

At the endpoint of the experiment, excised tumor tissue was homogenized in a Potter-Elvenhjem tissue homogenizer using ice-cold 50mM PBS with adjusted $\mathrm{pH} 7.4$, containing $1.15 \%$ $\mathrm{KCl}$. Next homogenates were centrifuged $(10,000 \mathrm{~g})$ at $4^{\circ} \mathrm{C}$ for $20 \mathrm{~min}$. The cell debris pellets were discarded while the supernatants were collected, divided into aliquots and stored at $-80^{\circ} \mathrm{C}$ for quantitative estimation of tumor growth biomarkers. Biomarkers as vascular endothelial growth factor (VEGF), Caspase-3 and Bcl-2 were measured using ELISA kit purchased from (Sunred Biological Technology Co. Ltd, China) according to manufacturer's protocols.

\section{Evaluation of in vivo Toxicity of HK-Loaded NCs}

After Mice were sacrificed, organs like heart, liver, spleen, lung, and kidneys were excised and accurately weighed. The immune organ index was determined according to the following formula. ${ }^{24}$

Immune organ index $=$ Weight of immune organs $(\mathrm{g})$

$$
\text { /Bodyweight }(\mathrm{g})
$$

Serum samples extracted from all animals were analyzed for evaluating aspartate aminotransferase (AST) and alanine aminotransferase (ALT) calorimetrically at wavelength of 340nm using (BioSystems, Egypt kits) to assess hepatic damage. Serum creatinine levels, an indicator for possible 
renal damage, were assayed by spectrophotometry at $490 \mathrm{~nm}$ with an enzymatic-colorimetric method using commercially available kits supplied by (Biodiagnostic, Egypt). Blood biochemistry was examined for the control group, free HK treated and HK-loaded NCs (F7) treated groups and compared with each other.

\section{Statistical Analysis}

Results for in vitro experiments were demonstrated as mean $\pm \mathrm{SD}$ and results from in vivo experiment, were presented as mean \pm SEM. Significant differences were evaluated statistically using one-way ANOVA followed by post-hoc Tukey's test. $\mathrm{P}<0.05$ was considered to be statistically significant for both in vitro and in vivo experiments.

\section{Results and Discussion}

Solvent displacement technique also called nanoprecipitation is the most applicable method for polymeric NCs preparation. It has been successfully used for entrapment of

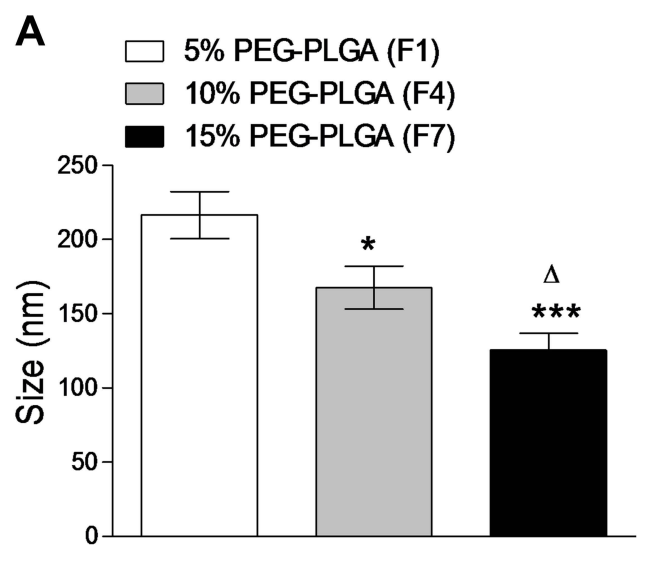

B

\section{Effect of PEG Content of the Polymer Backbone}

The physicochemical properties of three different formulations of HK-loaded NCs (F1, F4, and F7) made from different diblock copolymers depending on the PEG content were presented in (Figure 1). HK-loaded 15\% PEGPLGA NCs (F7) were significantly smaller in size than F1 $(\mathrm{p}<0.001, \mathrm{n}=3)$ and $\mathrm{F} 4(\mathrm{p}<0.05, \mathrm{n}=3)$ prepared from $5 \%$ to $10 \%$ PEG-PLGA diblock copolymer, respectively. Increasing the concentration of $\mathrm{PEG}$ in the polymeric backbone caused a decrease in the nanoparticles' size
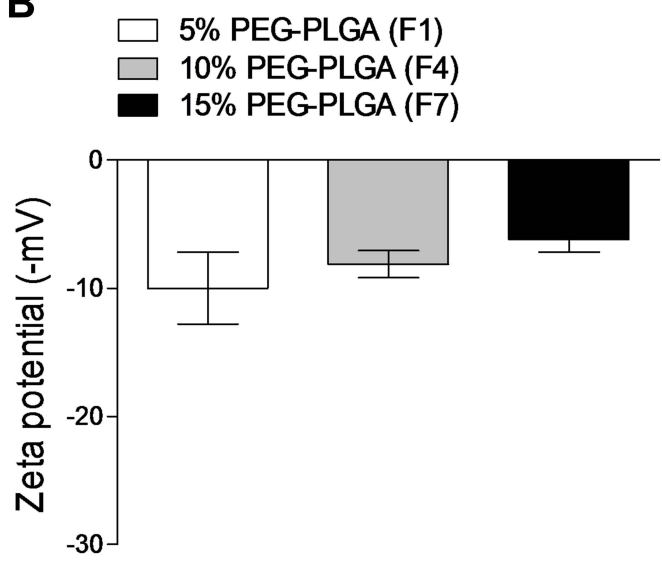

D

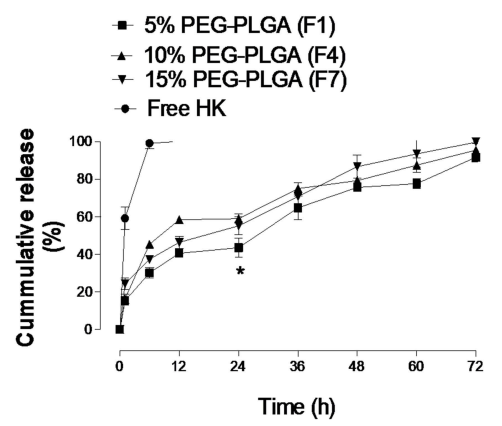

Figure I Effects of PEG content of the polymer backbone on NCs size (A), zeta potential (B), encapsulation efficiency (C) and HK in vitro release (D). Values are mean \pm SD for $(n=3)$. For $(\mathbf{A}-\mathbf{C}),{ }^{*} \mathrm{p}<0.05$, ** $\mathrm{p}<0.01$, ${ }^{* * *} \mathrm{p}<0.001$ compared with 5\% PEG-PLGA $(\mathrm{FI}) .{ }^{\Delta} \mathrm{p}<0.05$ compared with $10 \%$ PEG-PLGA (F4). 
with the largest size for F1 prepared from 5\% PEG-PLGA (Figure 1A). Increasing PEG content led to the formation of a shorter chain length of diblock copolymers. The particle size is increased by an increase in the hydrophobic segment ${ }^{37}$ which is a similar finding to that reported in other studies. ${ }^{10,12}$ All NC formulations showed a low polydispersity index (PDI) values ranging from 0.21 to 0.32 .

PEGylating, irrespective of PEG concentration, reduces the total negative surface charge of PLGA polymer. PEGylated PLGA NCs (F7) had a lower negative value of $(-6.21 \mathrm{mV})$ compared to F1 and F4 $(\mathrm{p}>0.05$, $\mathrm{n}=3$ ) (Figure 1B). The Presence of PEG as a non-ionic hydrophilic moiety decreases the zeta potential of PLGA polymer through masking a part of the polymer anionic charge which is responsible for the high negative surface charge values of PLGA polymer. ${ }^{38}$

HK loading and encapsulation efficiency were significantly increased by increasing the PEG concentrations in the polymer matrix. 15\% PEGylated PLGA NCs (F7) showed a significant increase in HK encapsulation efficiency compared to $\mathrm{F} 1(\mathrm{p}<0.01, \mathrm{n}=3)$ and $\mathrm{F} 4(\mathrm{p}<0.05$, $\mathrm{n}=3$ ) (Figure 1C). These results are attributed to the high amphiphilic property of 15\% PEG-PLGA copolymer which facilitate micelle formation in addition to the presence of high content of PEG chains which increases the surface area of the NCs and consequently increase the probability for a greater amount of drug to be loaded and thus increase its encapsulation efficiency. ${ }^{18}$ Drug entrapment efficiency depends on different parameters such as drug solubility, matrix composition, drug-polymer interactions, and the presence of functional groups in either the drug or matrix. ${ }^{11,39}$ PEG-PLGA is the polymer of choice for HKNCs formulations as PEG, showed a pronounced effect on drug-loading and interactions. ${ }^{18}$ High PEG content in case of $15 \%$ PEG-PLGA copolymer showed a higher rate of solidification compared to 5 and 10\% PEG-PLGA copolymer due to lower solubility in the organic phase which finally lead to higher entrapment of $\mathrm{HK}$ after organic solvent evaporation to form drug-loaded NCs. ${ }^{10}$

In vitro release profile of (F1, F4 and F7) showed that the $\mathrm{HK}$ burst release after $24 \mathrm{~h}$ was faster and significantly higher form the F7 which released approximately 55.24\% of HK compared to $43.53 \%$ released from the $\mathrm{F} 1$ ( $p<0.05$, $\mathrm{n}=3$ ) however non-significant difference was observed in case of $\mathrm{F} 4(\mathrm{p}>0.05, \mathrm{n}=3)$ (Figure 1D). Burst release phenomenon can be attributed to the drug attached to the surface of the NCs. ${ }^{40}$ Moreover, PEG chains are hydrophilic and can be easily dissolved in an aqueous release medium which derived the water to penetrate into the oily core, allowing HK to be released. Higher content of PEG accelerated the degradation rate because it facilitates higher water penetration compared with other NCs. ${ }^{41}$ The in vitro release profile of HK/DMSO control showed a $100 \%$ drug release achieved within the first $6 \mathrm{~h}$ which indicates satisfying the sink conditions besides the absence of non-specific drug absorption to the dialysis membrane. Moreover, this release profile can confirm the sustained drug release from nanocapsules compared to the control drug.

\section{Effect of Type of Oily Core}

PEGylated NCs encapsulating HK were formulated using one of the following oils (almond oil, castor oil or isopropyl myristate). HK showed its lowest solubility in isopropyl myristate $\left(0.99 \mathrm{mg} \mathrm{mL}^{-1}\right)$ which was significantly lower than castor oil $\left(1.81 \mathrm{mg} \mathrm{mL}^{-1}\right)(\mathrm{p}<0.05, \mathrm{n}=3)$. The highest HK solubility was achieved in almond oil $(2.56 \mathrm{mg}$ $\left.\mathrm{mL}^{-1}\right)$, at $37^{\circ} \mathrm{C}(\mathrm{p}<0.01, \mathrm{n}=3)$. HK-loaded $15 \%$ PEGylated NCs based on isopropyl myristate (F9) exhibited significantly bigger size $(177.5 \pm 15.4 \mathrm{~nm})$ compared to $\mathrm{NC}$ prepared from castor oil (F8) $(166.5 \pm 11.23)(\mathrm{p}<$ $0.01, n=3)$ and NC prepared from almond oil (F7) (125.5 \pm 11.5) $(\mathrm{p}<0.05, \mathrm{n}=3)$. A similar pattern was observed in the case of 5\% PEG-PLGA NCs; however, this behavior was not the same in the case of $10 \%$ PEG-PLGA NCs (Figure 2A). The PDI value in the case of NCs prepared from almond oil as an oily core was significantly lower than other PDI values for isopropyl myristate and castor oil NCs indicating more homogenous size distribution.

The type of oil has no significant effect on the $\zeta$ potential of different NCs formulations ( $p>0.05, n=3$ ) (Figure 2B). The encapsulation efficiency of all HKloaded NCs ranged from $(58.89 \pm 5.9$ to $94.18 \% \pm$ $1.8 \%$ ). Almond oil-based NCs demonstrated significantly higher encapsulation efficiency values compared to castor oil and isopropyl myristate-based formulation regardless of the type of the polymer $(\mathrm{p}<0.05, \mathrm{n}=3$ ) (Figure $2 \mathrm{C}$ ). This is might be attributed to the highest solubility of HK in almond oil which prevents its loss towards the aqueous phase leading to higher drug entrapment inside the oily core. Moreover, almond oil has a lower hydrophiliclipophilic balance (HLB 6), than castor oil (HLB 14) and isopropyl myristate (HLB 11.5); therefore, the nanocapsules based on almond oily core will be more suitable for HK loading due to its high lipophilicity. ${ }^{42}$ A similar finding was reported in previous studies. ${ }^{13,14}$ 
A

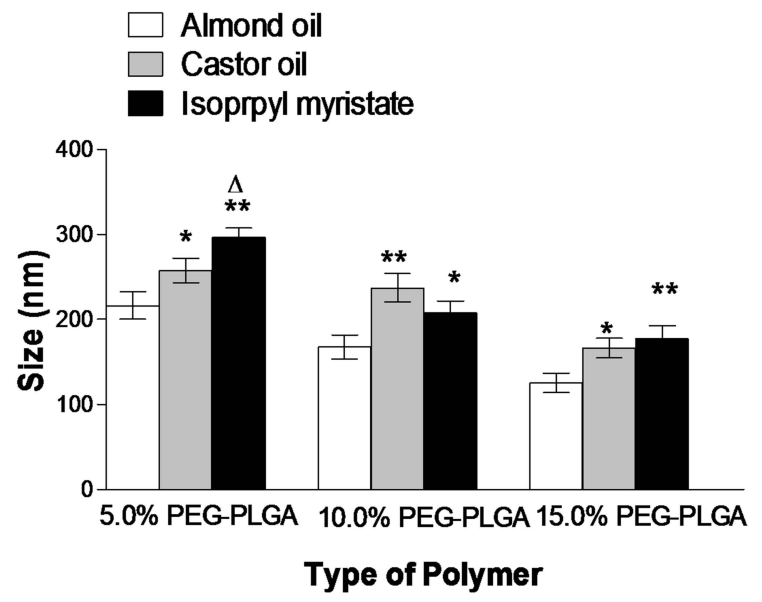

C

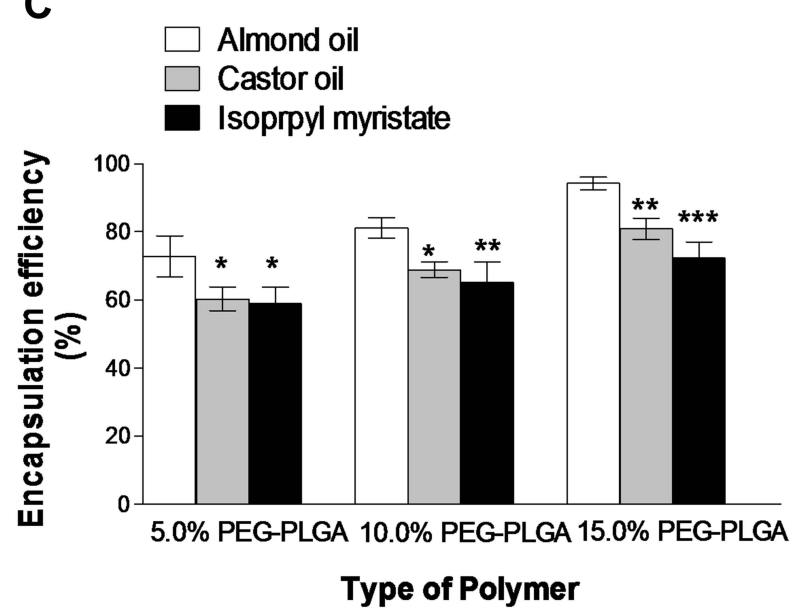

B
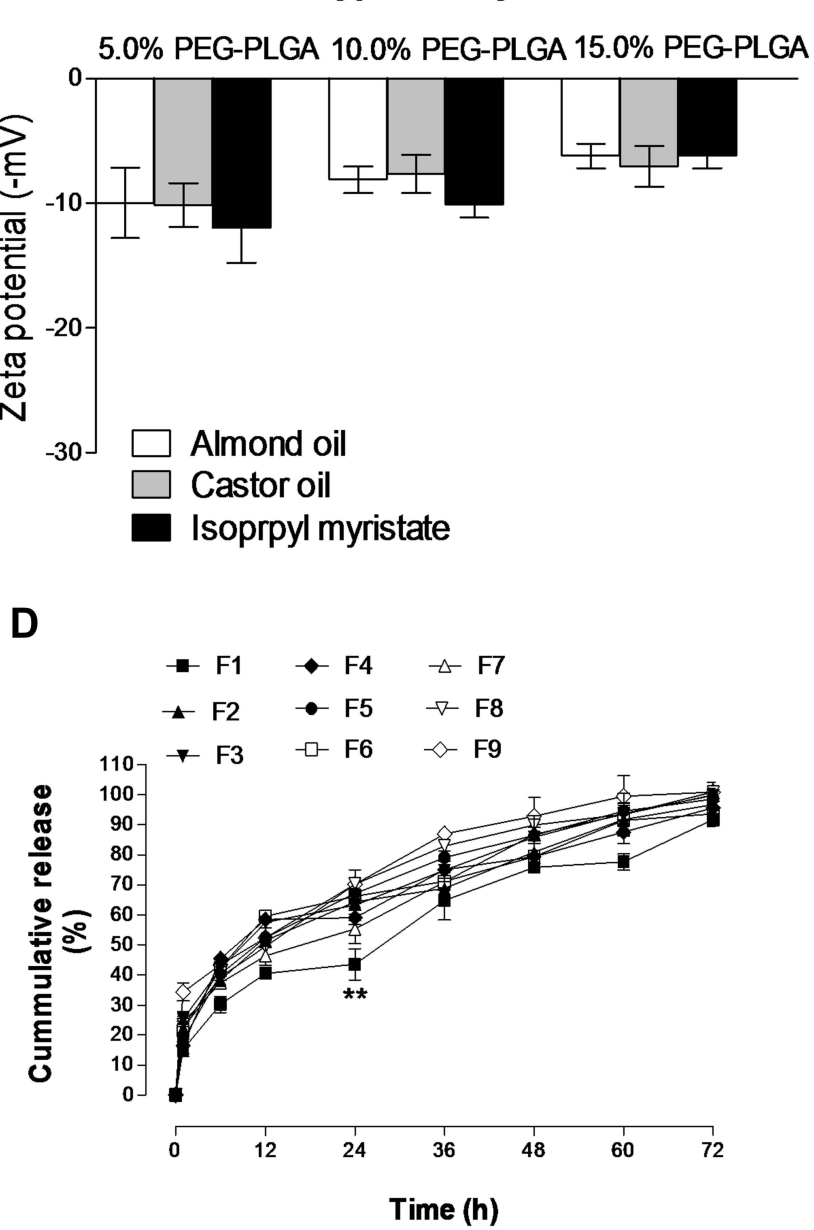

Figure 2 Effects of the type of oily core on NCs size $(\mathbf{A})$, zeta potential $(\mathbf{B})$, encapsulation efficiency $(\mathbf{C})$ and HK in vitro release $(\mathbf{D})$. Values are mean \pm SD for $(\mathrm{n}=3)$. For (A-C), ${ }^{*} \mathrm{p}<0.05,{ }^{* *} \mathrm{p}<0.01,{ }^{* * *} \mathrm{p}<0.001$ compared with almond oil for each polymer type. ${ }^{\Delta} \mathrm{p}<0.05$ compared with castor oil for each polymer type.

In vitro release profiles showed that different oily core significantly affected the initial burst release from different polymers (Figure 2D). Lower burst release had been observed from F1, F4, and F7 (prepared from almond oil) compared to other HK-loaded NCs prepared from castor oil or isopropyl myristate. F1 with almond oily core showed a significantly lower burst release of $43.53 \%$ compared to $65.34 \%$ and $63.23 \%$ from $\mathrm{F} 2$ and $\mathrm{F} 3$ prepared from castor oil and isopropyl myristate, respectively $(\mathrm{p}<0.01, \mathrm{n}=3)$. Similar results were observed in the case of HK-loaded NCs prepared from $15 \%$ PEG-PLGA polymer. F7 prepared with almond oil showed a significantly lower burst release of $55.24 \%$ compared to $70.55 \%$ and $76.49 \%$ from F8 and F9 prepared from castor oil and isopropyl myristate, respectively $(\mathrm{p}<0.05, \mathrm{n}=3)$. This might be attributed to different polymer solubility in different oils used. 15\% PEG-PLGA copolymer has lower solubility in almond oil compared to other PEGylated polymers. This lower solubility led to shorter solidification time and, consequently, leads to the formation of more dense NC structure slowing drug release. ${ }^{11}$ These results support the higher percentage of HK entrapment in the case of NCs prepared from $15 \%$ PEG-PLGA and almond oil due to the same reasons.

\section{Transmission Electron Microscopy}

Transmission electron micrograph of $\mathrm{F} 7$ was represented in (Figure 3). HK-loaded NCs showed a smooth spherical surface with a narrow size distribution. The average size and size distribution obtained from TEM was comparable to what obtained from Nanosizer.

\section{In vitro Stability}

Lyophilization was used to increase the long-term storage stability of HK-loaded NCs. In vitro stability results of three different HK-loaded NCs (F1, F4, and F7) are 
reported in Table 2. A slight non-significant increase in size, PDI $(\mathrm{p}>0.05, \mathrm{n}=3)$ meanwhile a slight decrease in zeta potential and \%E.E $(\mathrm{p}>0.05, \mathrm{n}=3)$ after 4 and 6 months was observed. This can be attributed to the role of PEG coat in stabilizing HK-loaded NCs and improving its aqueous solubility as previously reported. ${ }^{19,43}$ In addition, solidification of HK-loaded NCs by freeze-drying resulted in the stabilizing of HK-loaded NCs physio-chemical properties for 6 months after preparation.

\section{Cellular Uptake of HK-Loaded NCs}

This study aims to investigate the efficiency of cellular uptake of HK-loaded PEGylated PLGA NCs into MCF-7 breast cancer cells. In vitro, cellular uptake results are shown in (Figures 4 and 5). The quantitative flow cytometry analysis, which reflected the presence of the coumarin 6 tagged HKloaded NCs in MCF-7 cells after 24 hrs of treatment, is shown in (Figure 4). The percentage of cells with positive staining following treatment with $15 \%$ PEGylated NCs was significantly higher $(\mathrm{p}<0.01, \mathrm{n}=3)$ than all other NP formulations made from 5\% PEG-PLGA and 10\% PEG-PLGA. F7 showed higher cellular uptake with $71.42 \% \pm 6.94 \%$ positive cells, compared to $34.75 \% \pm 4.91 \%$ and $54.81 \% \pm 8 \%$ in the case of F1 and F4, respectively. Flow cytometry results were presented in (Supplementary Figure 1). These results showed that F7, with the lowest particle size of $(125.5 \pm 11.5)$, lowest zeta potential of $(-6.21 \pm 0.97 \mathrm{mV})$ and highest PEG content gave rise to the greatest uptake by MCF-7 breast cancer cells. 15\% PEGylated PLGA NCs showed significantly higher cellular uptake when compared to 5\% and 10\% PEG-PLGA NCs, due to PEGylation pronounced effect on decreasing nanoparticles size and negative zeta potential. This suggests that particle size and zeta potential are considered to be the key determinant factors of cellular uptake. ${ }^{11,44}$

Confocal scanning microscopy images confirmed that F7 exhibited the largest uptake by MCF-7 cells (Figure 5). HKloaded NCs (F7) were primarily localized in the cytoplasm, while some fluorescence intensity was observed around the nucleus (Figure 5G-I). This confirms sub-cellular drug delivery of honokiol-loaded NCs (F7) that will release HK from the biodegradable nanocapsule into the cancer cells. The coumarin 6 solution uptake by MCF-7 cells showed minimum cellular uptake (Figure 5D-F). Confocal laser microscopy images of F1 and F4 were represented in (Supplementary Figure 2). Based on these quantitative and qualitative results, it is clear that $15 \%$ PEGylated PLGA NP showed maximum cellular uptake due to optimum physio-chemical properties. Therefore, F7 was selected for further in vitro and in vivo studies due to its superior physicochemical properties and enhanced cellular uptake into breast cancer cells.
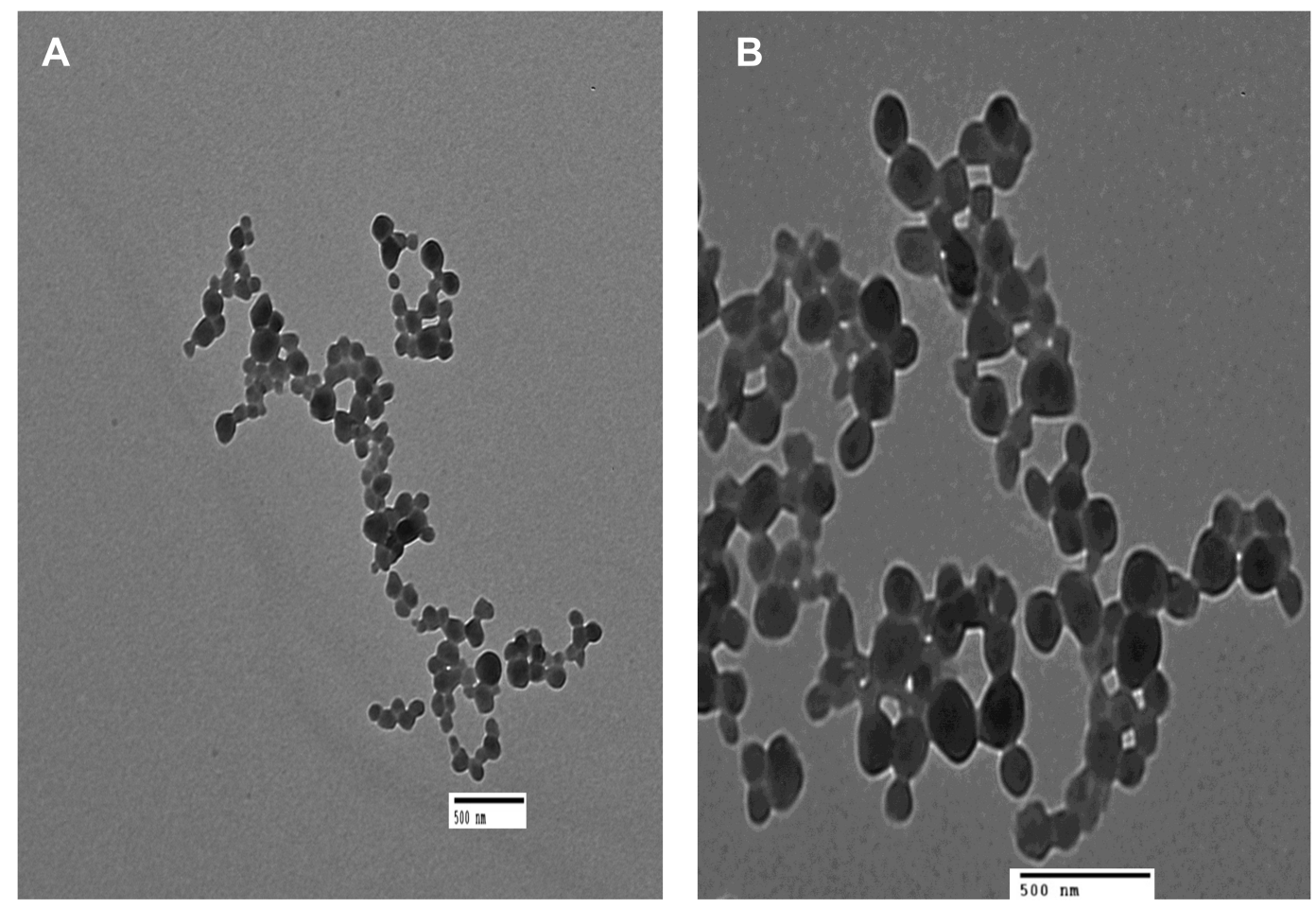

Figure 3 TEM images of HK NCs (F7) after preparation, (A) Mag $\times 1000$ and (B) Mag $\times 2000$. 
Table 2 In vitro Stability Results of HK-Loaded NCs

\begin{tabular}{|l|l|l|l|l|l|}
\hline Formulation Identifier & Time (Month) & Size (nm) & PDI & $\zeta$-Potential (mV) & \% E.E \\
\hline FI & 0 & $216.52 \pm 15.95$ & $0.21 \pm 0.05$ & $-9.97 \pm 2.81$ & $72.89 \pm 6.01$ \\
& 2 & $225.57 \pm 13.71$ & $0.23 \pm 0.04$ & $-9.52 \pm 2.52$ & $70.11 \pm 5.69$ \\
& 4 & $237.41 \pm 20.11$ & $0.22 \pm 0.07$ & $-8.17 \pm 3.19$ & $66.89 \pm 8.77$ \\
& 6 & $247.22 \pm 17.32$ & $0.25 \pm 0.06$ & $-9.18 \pm 4.42$ & $65.22 \pm 6.01$ \\
\hline F4 & 0 & $167.51 \pm 14.43$ & $0.28 \pm 0.04$ & $-8.11 \pm 1.04$ & $81.19 \pm 3.02$ \\
& 2 & $181.42 \pm 11.99$ & $0.29 \pm 0.07$ & $-7.22 \pm 2.13$ & $77.59 \pm 5.22$ \\
& 4 & $201.75 \pm 16.18$ & $0.28 \pm 0.06$ & $-7.99 \pm 1.46$ & $75.15 \pm 3.66$ \\
& 6 & $209.31 \pm 19.25$ & $0.3 \pm 0.05$ & $-7.01 \pm 1.69$ & $74.66 \pm 5.12$ \\
\hline F7 & 0 & $125.12 \pm 11.51$ & $0.19 \pm 0.06$ & $-6.21 \pm 0.97$ & $94.18 \pm 1.82$ \\
& 2 & $128.72 \pm 19.61$ & $0.24 \pm 0.02$ & $-5.76 \pm 1.29$ & $92.88 \pm 3.12$ \\
& 4 & $137.44 \pm 16.28$ & $0.23 \pm 0.03$ & $-6.19 \pm 2.47$ & $90.77 \pm 2.24$ \\
& 6 & $147.39 \pm 14.22$ & $0.25 \pm 0.07$ & $-5.89 \pm 3.68$ & $88.5 \pm 6.72$ \\
\hline
\end{tabular}

Note: All results are presented as mean \pm SD with $n=3$.

In vitro Cytotoxicity of HK-Loaded NCs The anti-proliferative action of HK-loaded NCs (F7) on the MCF-7 cell line was estimated by MTT assay for 24 , 48 and $72 \mathrm{hrs}$ after treatment at 5,10 and $20 \mu \mathrm{M}$ of free honokiol and HK-loaded NCs (Figure 6). The dose-effect curves were plotted to measure the drug concentration that caused $50 \%$ growth inhibition $\left(\mathrm{IC}_{50}\right)$ using GraphPad Prism ${ }^{\circledR}$ software. To calculate $\mathrm{IC}_{50}$, a series of different drug concentrations that resulted in different growth inhibition values were plotted as a linear standard curve (Log value of drug concentrations vs $\%$ growth inhibition). The linear regression equation of the dose-effect curve was used to calculate the $\mathrm{IC}_{50}{ }^{20}$ The results showed that the blank NCs had no cytotoxicity on breast cancer cells. Treatment with honokiol showed a significant reduction in cell viability compared to control $(\mathrm{p}<0.05, \mathrm{n}=3)$. Free HK showed a dose-dependent cytotoxic action as cell viability decreased with increasing the dose from 5 to 20 $\mu \mathrm{M}$. Treatment with HK-loaded NCs (F7) reduced cell viability in a dose-dependent manner meanwhile it maintained its cytotoxic action up to three days after treatment due to sustained cytotoxic action (Figure 6A). After $24 \mathrm{hrs}$ of treatment, the mean $\mathrm{IC}_{50}$ value of HK-loaded NCs (F7) in MCF-7 cells was approximately $20 \pm 2.3 \mu \mathrm{M}$, which is significantly lower than calculated $\mathrm{IC}_{50}$ of free honokiol $(52.63 \pm 5.4 \mu \mathrm{M})(\mathrm{p}<0.001, \mathrm{n}=3)$. The mean IC50 value for HK-loaded NCs (F7) in EAC cells was approximately $10 \mu \mathrm{M}$, compared to $27.7 \mu \mathrm{M}$ of free honokiol which was achieved within 3 hrs $(\mathrm{p}<0.001, \mathrm{n}=3$ ) (Figure 6B). Based on these results, HK-loaded NCs (F7) achieved significant cytotoxic action compared to free HK due to successful
HK delivery to the subcellular site of action ${ }^{2}$ meanwhile preserving its anti-cancer activity after formulation.

\section{In vivo Anti-Tumor Activity}

In the present study, we investigated for the first time the in vivo effects of HK and HK-loaded PEG-PLGA NCs on

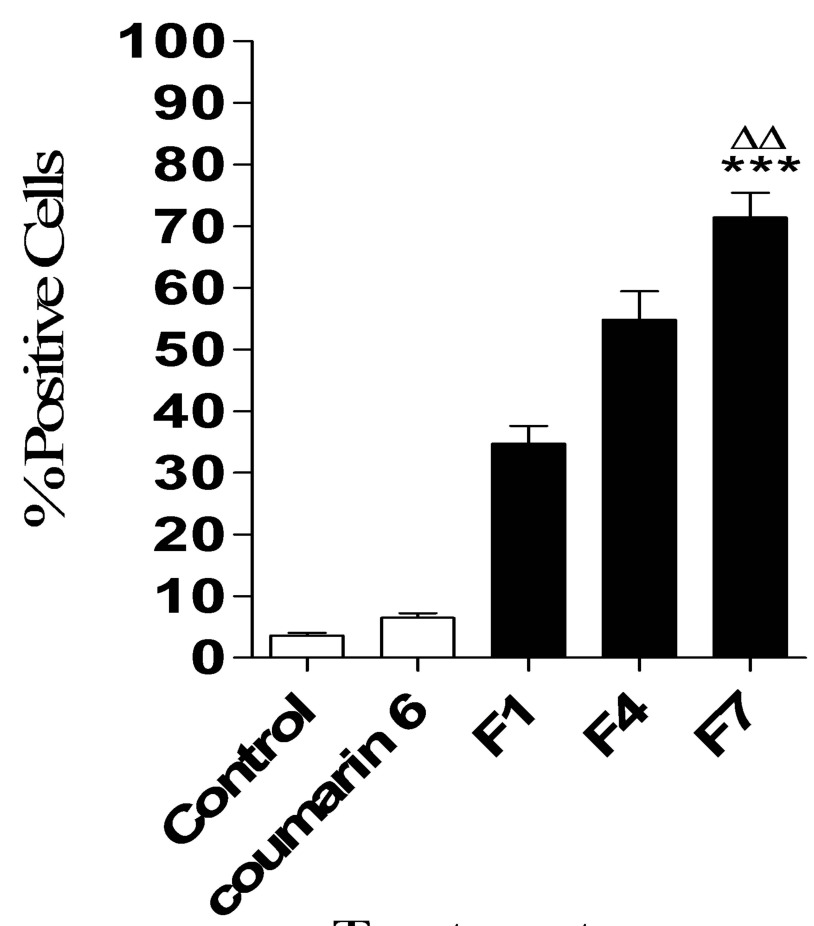

Treatment

Figure 4 Quantitative cellular uptake of different types of HK NCs (FI, F4, and F7) determined by flow cytometry after $24 \mathrm{hrs}$ of treatment. Results are represented as the percentage of positive cells showing cellular uptake of each NC. Values are mean $\pm S D$ for $(n=3)$. ${ }^{* * *} p<0.001$ compared with control, coumarin 6 and $\mathrm{FI}$ groups. ${ }^{\Delta \Delta} \mathrm{P}<0.00 \mathrm{I}$ compared with $\mathrm{F} 4$. 

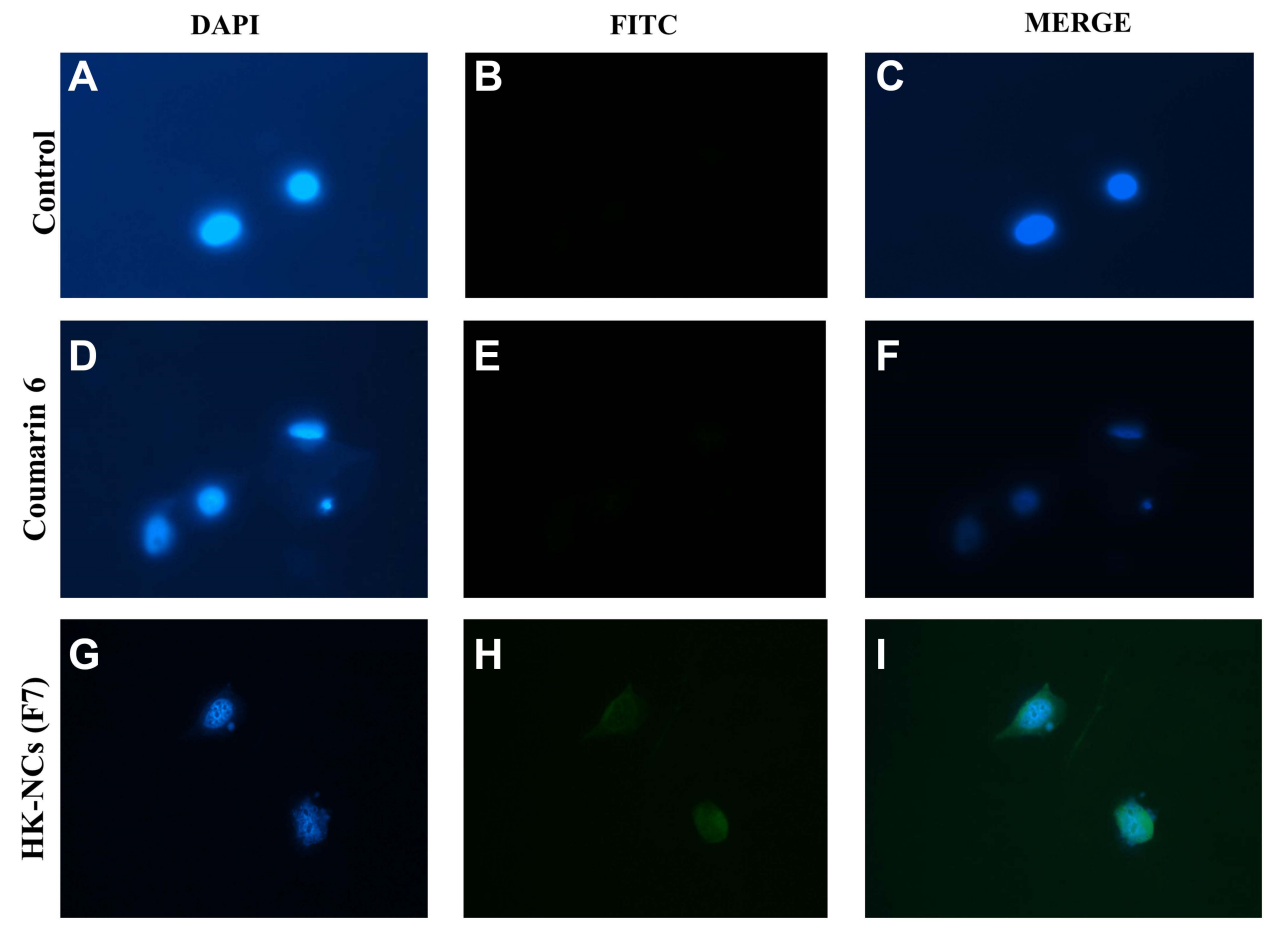

Figure 5 Confocal laser scanning microscopy images of MCF-7 control cells (A-C), cells treated with coumarin 6 (D-F) and coumarin 6 tagged HK NC (F7) (G-I) after $24 \mathrm{hrs}$ of treatment.

the proliferation of SEC cells in SEC tumor-bearing mice. Solid Ehrlich Carcinoma (SEC) xenograft model is a wellestablished in vivo model in mice. It was commonly used to study the effect of different chemotherapeutic drugs on the treatment of breast cancer. ${ }^{45}$ This model reflects highgrade malignancy due to its high virulence ability, infiltrative nature, and quick development. ${ }^{46}$ Therefore, the SEC model is used to study the anti-cancer effect of HK against breast cancer after systemic administration in vivo.

The in vivo anti-tumor activity in mice-bearing SEC tumors after treatment with $\mathrm{HK}$ was measured by the tumor growth inhibition effect (Figure 7). After 11 days of HK treatment, the size of tumor mass in animals treated with F7 was significantly lower compared to the free drug-treated group and the control group $(\mathrm{p}<0.05, \mathrm{n}=8)$. Animals treated with HK solution, at a dose of $\left(15 \mathrm{mg} \mathrm{kg}^{-1}\right)$ showed that HK was efficient in restraining further tumor growth after 11th day and a non-significant increase in tumor size was observed $(\mathrm{p}>$ $0.05, \mathrm{n}=8$ ). The average tumor size of animals treated with free $\mathrm{HK}$ at the end of the treatment was found to be $906.75 \pm$ $105.32 \mathrm{~mm}^{3}$ (Figure 7A) and the percentage tumor growth inhibition (\% TGI) was approximately 35\% (Figure 7B). A more pronounced effect was noticed in animals treated with HK-loaded 15\% PEG-PLGA NCs. A sharp decrease in tumor size was observed starting from the 11th day of treatment and continued at each time point until the end of the experiment $(p<0.001, n=8)$. The average size of tumor mass at the end of the treatment was found to be decreased to $266.89 \pm 115.69 \mathrm{~mm}^{3}$ and the \% TGI was $80.85 \%$ (Figure $7 \mathrm{~B}$ ). It is evident that the HK-loaded NCs (F7) possessed a greater anti-tumor activity when compared to free $\mathrm{HK}$ due to the significant reduction in tumor size.

At the end of the treatment, all animals were sacrificed. A photograph of animals bearing a tumor at the end of the experiment was shown in (Figure 8A). The difference in tumor weights between control and treated animals was exhibited in (Figure 8B). The average tumor weight in the control group after treatment was $2.16 \pm 0.55 \mathrm{~g}$. Animals treated with free drug, the average tumor weight was decreased to $1.2 \pm 0.29$ $\mathrm{g}$ with a percentage reduction of $45 \%$. On the other hand, the mean tumor weight of animals treated with F7 was $0.315 \pm$ $0.14 \mathrm{~g}$. The percentage reduction in tumor weights was $85.5 \%$ which is statistically significant compared to free drug-treated mice $(\mathrm{p}<0.001, \mathrm{n}=8)$. The drug dose used for this study was (15 mg kg${ }^{-1}$ ) which is significantly lower than other published doses for similar in vivo work. ${ }^{2,24}$

\section{Tumor Growth Biomarkers}

Previous studies have proven that the anti-cancer activity of $\mathrm{HK}$ is directly related to its role in regulating various 


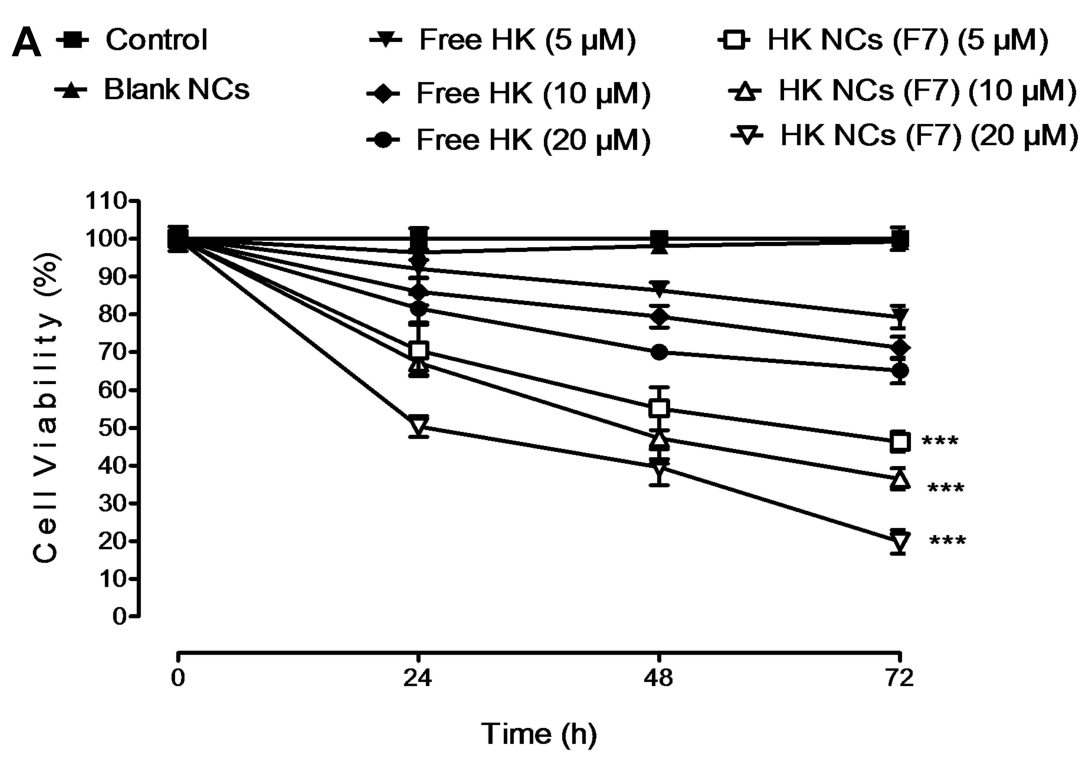

B
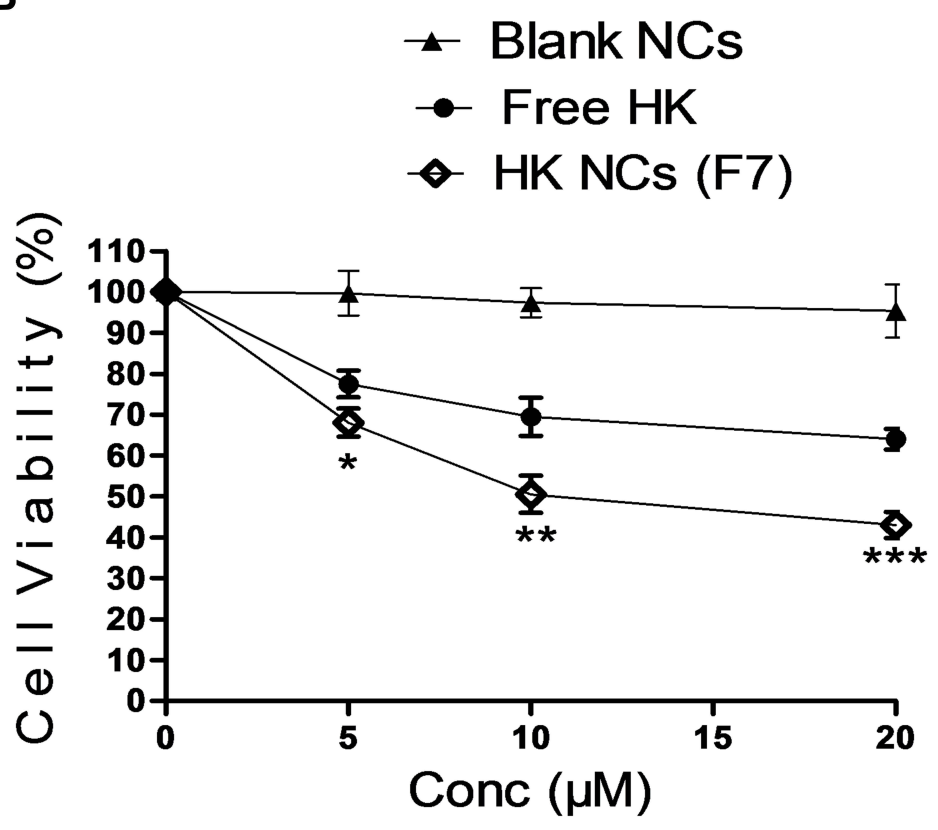

Figure 6 Cell viability results of different doses of free HK and HK NCs (F7) after 24, 48 and 72 hrs using MCF-7 cell line (A) and EAC cell line (B). Values are expressed as mean \pm SD for $(n=3)$. For $(\mathbf{A}$ and $\mathbf{B}){ }^{*} p<0.05$, **p $<0.01$, *** $p<0.001$ compared with free HK of the same dose.

signaling pathways. These include the upregulation of epithelial tumor markers and downregulation of mesenchymal tumor markers leading to apoptosis. Additionally, HK possesses an anti-metastatic effect through inhibition of angiogenesis (via the down-regulation of VEGF), invasion and migration. ${ }^{2}$ Three different tumor markers were used in this study. Tumor growth biomarker results were represented in (Figure 9). VEGF-1 is one of the most important angiogenic factors, which mediate the formation of new blood and lymphatic vessels. It was clear from ELISA results that HK- loaded NCs (F7) exhibited a high antiangiogenic activity as it showed a significant decrease in VEGF-1 level in tumor tissue compared to control animals and free HK treated group ( $\mathrm{p}<0.001, \mathrm{n}=8$ ). Honokiol causes blockade of VEGF receptor 2 autophosphorylation and hence interfering with Rac activation which is mandatory for VEGF-induced endothelial migration and proliferation. This can explain the potential honokiol anti-angiogenic role in cancer cells. ${ }^{47}$ Apoptosis is a form of programmed cell death that is precisely regulated. It is one of the most important types of 


\section{$A-$ Control - Blank NCs}

\section{$\rightarrow$ Free HK $(15 \mathrm{mg} / \mathrm{kg})$ HK NCs (F7) $(15 \mathrm{mg} / \mathrm{kg})$}

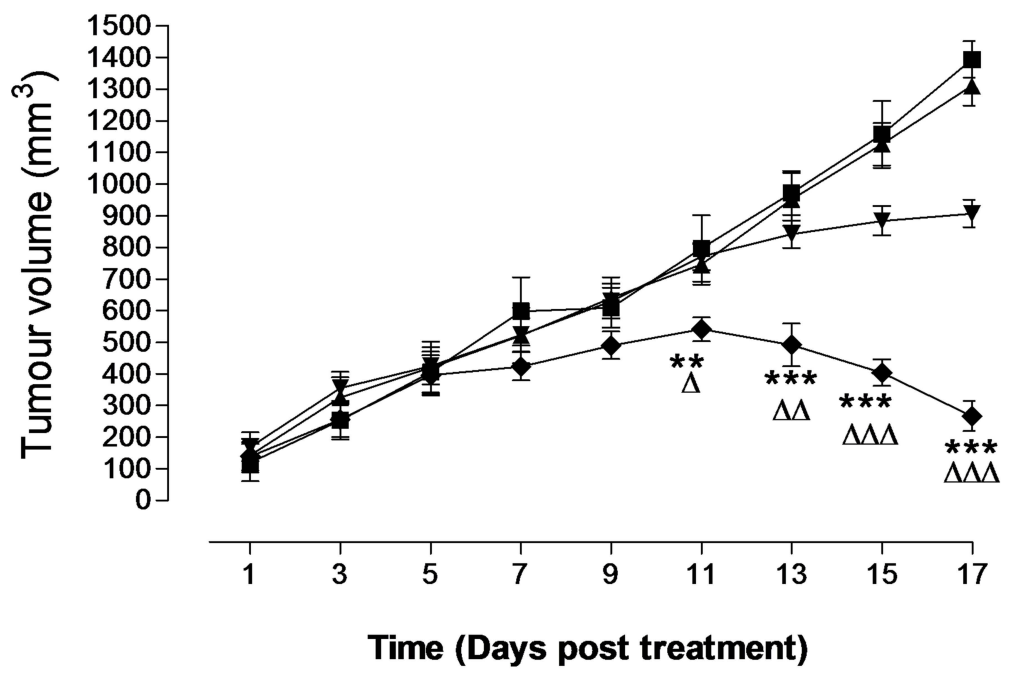

B $\square$ HK NCs (F7) (15 mg/kg)

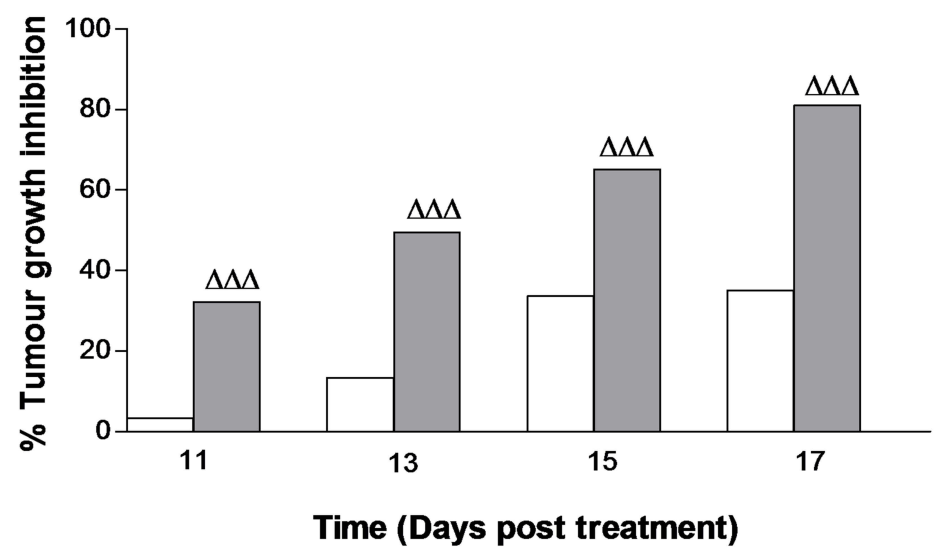

Figure 7 Tumor volume recorded for the studied animal groups every 2 days from the Ist day of the treatment to the last record on the I7th day (the end of the experiment). Values are mean $\pm \mathrm{SEM}$ for $(\mathrm{n}=8)$. ${ }^{* *} \mathrm{P}<0.0 \mathrm{I}$, ${ }^{* * *} \mathrm{P}<0.00 \mathrm{I}$ compared with control group. ${ }^{\Delta} \mathrm{P}<0.05,{ }^{\Delta \Delta} \mathrm{P}<0.0 \mathrm{I},{ }^{\Delta \Delta \Delta} \mathrm{P}<0.00 \mathrm{I}$ compared with animal treated by free $\mathrm{HK}$ at a dose of $\left(15 \mathrm{mg} \mathrm{kg}^{-1}\right)(\mathbf{A})$. Percentage tumor growth inhibition (\% TGI) in animals treated with free $\mathrm{HK}$ or $\mathrm{HK} \mathrm{NCs} \mathrm{(F7)} \mathrm{at} \mathrm{a} \mathrm{dose} \mathrm{of}\left(15 \mathrm{mg} k \mathrm{~kg}^{-1}\right) \triangle \Delta \Delta \mathrm{P}<0.00 \mathrm{I}$ compared with animals treated by free HK (B).

cellular biomolecular signaling pathways that participate in carcinogenesis. ${ }^{48}$ Lack of ability to undergo apoptosis is the major cause of both tumorigenesis and tumor growth. ${ }^{49}$ There are three well-known pro-apoptotic pathways, including the death receptor, mitochondrial, and endoplasmic reticulum enzyme pathway. The B-cell lymphoma 2 (Bcl-2) groups play a major role in the regulation of the mitochondrial pathway. ${ }^{50}$ Caspase 3 is considered one of the key mediators of apoptosis especially in the case of breast cancer. ${ }^{51}$ It was clear from ELISA results that HK-loaded NCs (F7) exhibited a high antiangiogenic activity as it showed a significant decrease in VEGF-1 level in tumor tissue compared to control animals and free HK treated group ( $\mathrm{p}<0.001, \mathrm{n}=8)$. Apoptotic biomarker results showed that there is a significant increase in caspase-3 level in tumor tissue compared to control and HK treated group $(\mathrm{p}<0.001$, $\mathrm{n}=8$ ). On the other hand, HK-loaded NCs (F7) showed a significant decrease in pro-apoptotic Bcl-2 level in tumor 


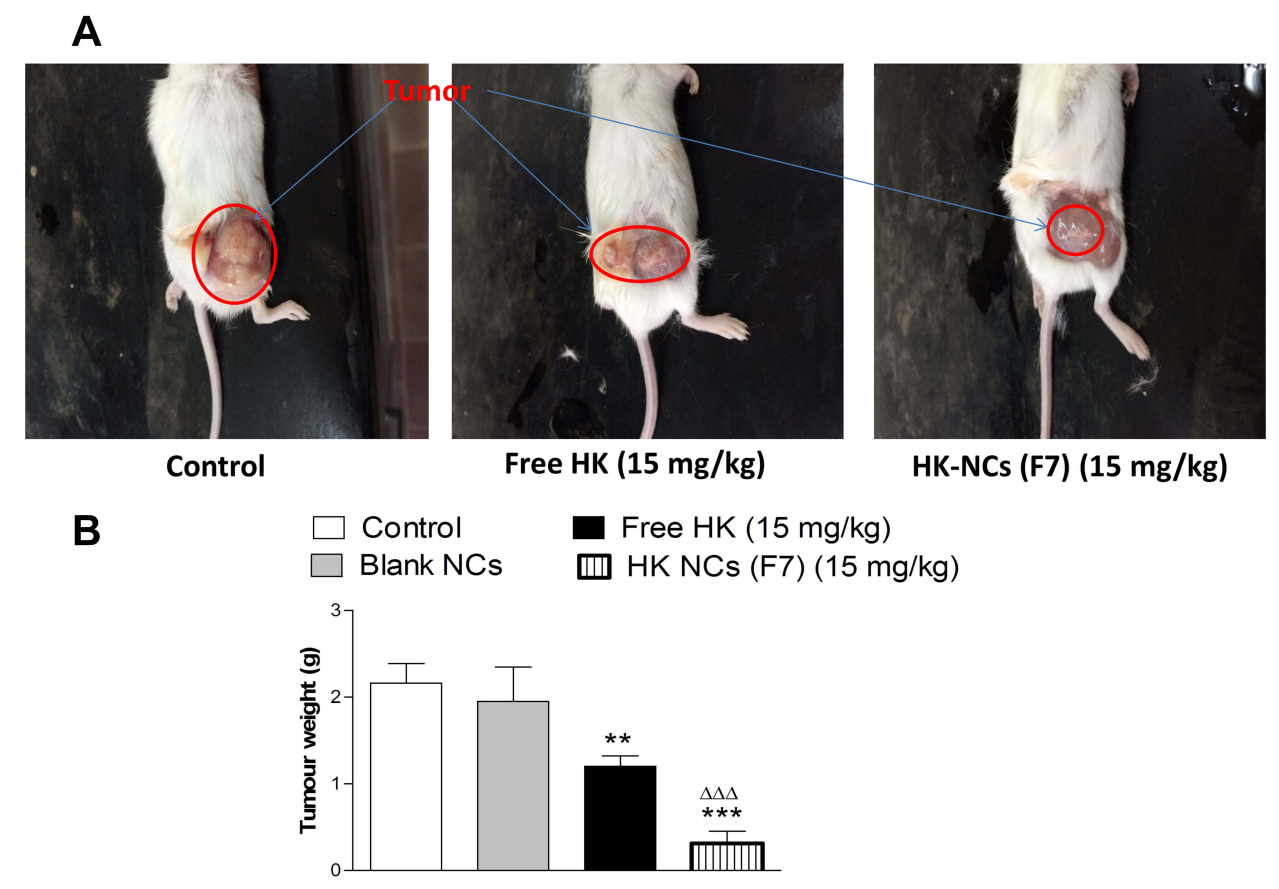

Figure 8 Photographs of control animals and animals treated with free HK and HK NCs (F7) at a dose of ( 15 mg kg $\left.{ }^{-1}\right)$ (A). Tumor weight of studied groups after the end of the experiment. Values are mean \pm SEM for $(n=8)$. ${ }^{* * P}<0.01$, ${ }^{* * *} \mathrm{P}<0.00 \mathrm{I}$ compared with control group. ${ }^{\Delta \Delta \Delta} \mathrm{P}<0.00 \mathrm{I}$ compared with animals treated by free $\mathrm{HK}$ at a dose of $\left(15 \mathrm{mg} \mathrm{kg}^{-1}\right)(\mathbf{B})$.

tissue homogenate $(\mathrm{p}<0.001, \mathrm{n}=8)$. These results confirm that HK-loaded NCs had a powerful antiangiogenic and apoptotic activity compared to free drug. Honokiol was confirmed to promote cellular apoptosis in both human and mouse malignant cells via activating caspase-3, p53/PI3K/ Akt/mTOR, and ROS/ERK1/2 signaling pathway. Also, honokiol activates mitochondrial Sirt3 that disturb electron transport chain function, inducing mitochondrial fusion that enhances apoptosis. ${ }^{52,53}$

\section{In vivo Safety of HK-Loaded NCs}

All animals appeared healthy throughout the whole in vivo study meanwhile no substantial body weight loss was observed. There were no signs of decreased activity or abnormal behavior, which indicates no toxicity caused by treatment with either free drug or drug-loaded NCs. The measured weight gain and the immune organ index of treated and untreated mice are shown in Table 3 . The body weight of all mice increased with time. The weight gain of control mice was about $3.3 \pm 0.99 \mathrm{~g}$. Animals treated with free HK and HKloaded NCs (F7) showed a non-significant increase in weight gain (Figure 10). Honokiol was reported to have a nonsignificant effect on the normal growth and development of mice. Treatment of mice with HK as a chemopreventive agent against cancer showed a non-significant effect on weight gain. ${ }^{54}$ Its action as non-adipogenic PPAR $\gamma$ agonist significantly suppressed weight gain only in diabetic mice. ${ }^{8}$ Moreover, animals' treated groups showed a non-significant difference in immune organ index compared to control mice $(p>0.05, n=8)$. It is clear that the liver and the kidney are the most important organs for the metabolism and elimination of drugs in the body, and it is also the most vulnerable organs to damage by drug-induced effects. Therefore, biochemical assays were also used to ensure the safety of HK treatment. The effect of free HK and HK-loaded NCs (F7) on liver and kidney functions is reordered in Table 4. Extensive tissue injury resulted in the release of ALT and AST into the blood. Liver injury is associated with elevated levels of ALT. All treated animals exhibited no significant effect in ALT and AST levels in the serum samples compared with the control group $(p>0.05, n=8)$. On the other hand, kidney function measured by serum creatinine level demonstrated a non-significant increase in animal treated groups compared with control animals $(p>0.05)$. Therefore, it can be concluded that HK-loaded NCs were clearly safe after systemic administration of a dose of $15 \mathrm{mg} \mathrm{kg}^{-1}$ by intraperitoneal injection.

The major challenge of anti-cancer therapeutics is to reach their predetermined cellular and subcellular target sites, meanwhile minimizing their action at nonspecific sites. Herein, surface modification of HK-loaded NCs 
A
Control
Free HK (15 mg/kg)
Blank NCs
四 HK NCs (F7) (15 mg/kg)

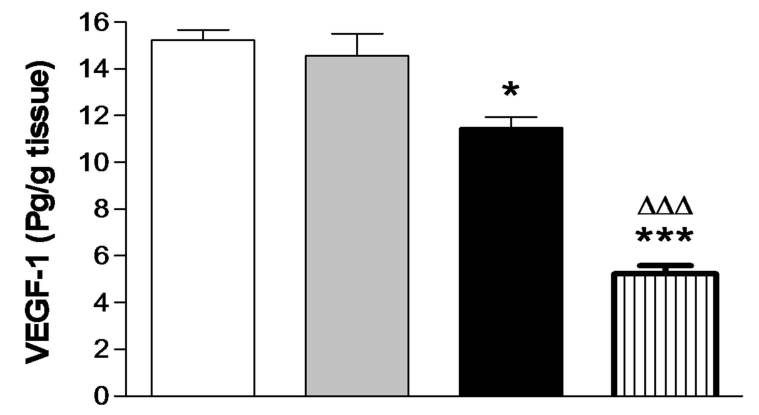

B

$\square$ Control $\square$ Free HK $(15 \mathrm{mg} / \mathrm{kg})$

$\square$ Blank NCs 血 HK NCs (F7) (15 mg/kg)

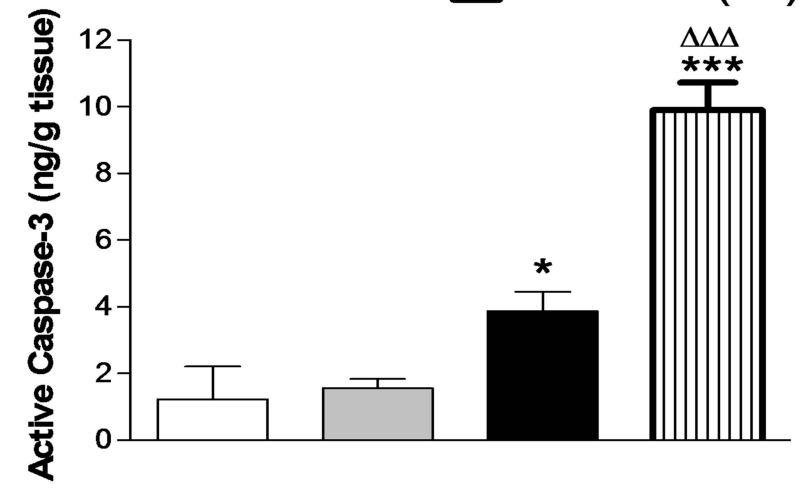

C

Control

Blank NCs

Free HK (15 mg/kg) 四 HK NCs (F7) (15 mg/kg)

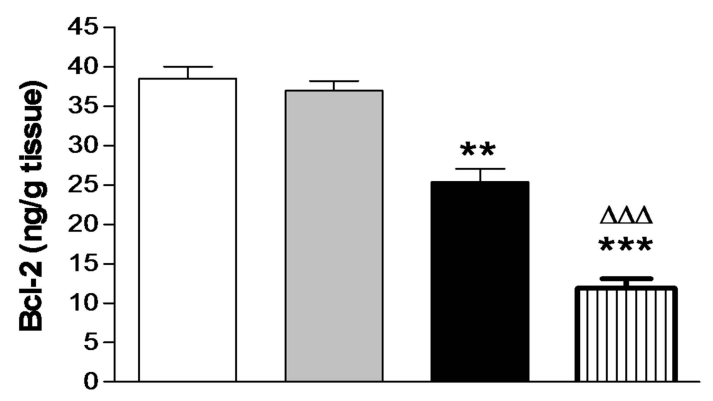

Figure 9 Tumor growth biomarkers of studied groups after the end of the experiment, VEGF-I $(\mathbf{A})$, Caspase-3 $(\mathbf{B})$ and $\mathrm{Bcl}-2(\mathbf{C})$. Values are mean \pm SEM for $(\mathrm{n}=8)$. $* \mathrm{P}<0.05,{ }^{*} * \mathrm{P}<0.01,{ }^{* * *} \mathrm{P}<0.001$ compared with control group. ${ }^{\Delta \Delta \Delta} \mathrm{P}<0.001$ compared with animals treated by free $\mathrm{HK}$ at a dose of $\left(\mathrm{I} 5 \mathrm{mg} \mathrm{kg}{ }^{-1}\right)$.

with polyethylene glycol (PEG) was adopted as a strategy to prolong circulation time, minimize nonspecific uptake, and facilitate specific passive tumortargeting through the well-known enhanced permeability and retention effect (EPR). The rapid uptake of PLGA nano-systems by the reticuloendothelial system, mainly by the aid of liver and spleen macrophages would be significantly decreased by modifying their surface with polyethylene glycol (PEG). ${ }^{12,55}$ The presence of PEG chains on the surface can protect HK-loaded NCs from capture by macrophages improves its sub-cellular delivery and hence maximize its anti-cancer activity.

\section{Conclusion}

The novelty of this piece of work depends on two aspects; the use of biocompatible PEGylated PLGA oil-cored 
Table 3 Effect of HK-Loaded NCs on the Immune Organ Index in Mice

\begin{tabular}{|l|l|l|l|l|l|}
\hline \multirow{2}{*}{$\begin{array}{l}\text { Animal } \\
\text { Group }\end{array}$} & \multicolumn{4}{|l|}{ Organ Index (mg/kg) } \\
\cline { 2 - 6 } & Heart & Lung & Liver & Kidneys & Spleen \\
\hline Control & $3.54 \pm$ & $4.21 \pm$ & $6.94 \pm$ & $7.29 \pm$ & $2.11 \pm$ \\
& 0.23 & 0.28 & 0.55 & 0.17 & 0.25 \\
Blank NCs & $3.14 \pm$ & $4.11 \pm$ & $6.77 \pm$ & $7.51 \pm$ & $1.99 \pm$ \\
& 0.66 & 0.66 & 0.11 & 0.29 & 0.77 \\
Free HK & $3.94 \pm$ & $4.01 \pm$ & $6.54 \pm$ & $7.44 \pm$ & $2.22 \pm$ \\
$(\mathrm{I5} \mathrm{mg} \mathrm{kg}$ & \\
HK-loaded & 0.11 & 0.58 & 0.93 & 0.22 & 0.19 \\
NCs (F7) & $3.12 \pm$ & $4.01 \pm$ & $7.04 \pm$ & $7.08 \pm$ & $1.89 \pm$ \\
$\left(\mathrm{I} 5 \mathrm{mg} \mathrm{kg}^{-1}\right)$ & 0.74 & 0.32 & 0.25 & 0.27 & 0.95 \\
\hline
\end{tabular}

Note: Values are represented as mean \pm SEM with $n=8$.

nanocapsules for honokiol loading, and in vivo application of optimum HK-loaded NCs for breast cancer treatment using SEC model. In an attempt to optimize the formulation of HK-loaded NCs, different PEG-PLGA diblock copolymers and different types of oily core were studied. Optimum HK-loaded NCs were prepared from 15\% PEG-PLGA with the smallest size, narrow polydispersity index, highest drug loading and highest cellular uptake by MCF-7 breast cancer cells compared with other HK-loaded NCs. Optimum HKloaded NCs exhibited a significant cytotoxic action against MCF-7 and EAC breast cancer cells due to their lower $\mathrm{IC}_{50}$ compared to free HK. Moreover, in vivo results supported the enhanced anti-tumor activity of HK-loaded NCs as approximately $80 \%$ reduction in tumor growth and $85 \%$ inhibition in tumor weight were observed after treatment

\section{Control Free HK $(15 \mathrm{mg} / \mathrm{kg})$ Blank NCs 四 HK NCs (F7) (15 mg/kg)}

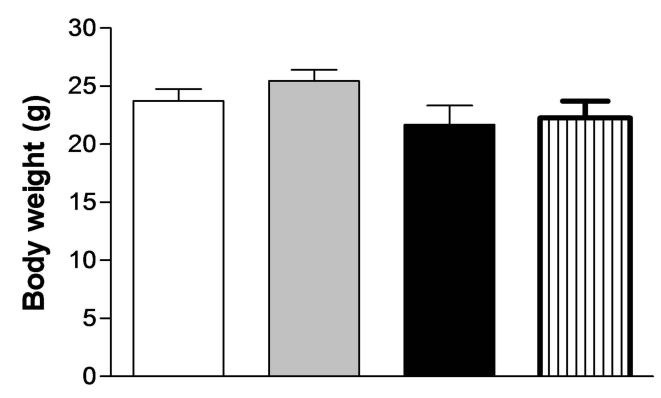

Figure 10 Bodyweight of studied animal groups treated with free HK and HK NCs (F7) at a dose of $\left(15 \mathrm{mg} \mathrm{kg}^{-1}\right)$ after the end of the experiment, Values are mean \pm SEM for $(n=8)$.
Table 4 Effect of HK-Loaded NCs on the Serum Level of Blood Biochemical Parameters

\begin{tabular}{|c|c|c|c|}
\hline Animal Group & $\begin{array}{l}\text { ALT } \\
\text { (Units } \\
\mathbf{L}^{-1} \text { ) }\end{array}$ & $\begin{array}{l}\text { AST } \\
\text { (Units } \\
\mathbf{L}^{-1} \text { ) }\end{array}$ & $\begin{array}{l}\text { Serum } \\
\text { Creatinine } \\
\left(\mathrm{mg} \mathrm{dL}^{-1}\right)\end{array}$ \\
\hline Control & $\begin{array}{l}18.55 \pm \\
4.12\end{array}$ & $\begin{array}{l}37.58 \pm \\
6.47\end{array}$ & $0.49 \pm 0.26$ \\
\hline Blank NCs & $\begin{array}{l}16.43 \pm \\
5.36\end{array}$ & $\begin{array}{l}41.16 \pm \\
7.53\end{array}$ & $0.57 \pm 0.08$ \\
\hline Free $\mathrm{HK}\left(15 \mathrm{mg} \mathrm{kg}^{-1}\right)$ & $\begin{array}{l}21.91 \pm \\
2.77\end{array}$ & $\begin{array}{l}37.16 \pm \\
10.99\end{array}$ & $0.56 \pm 0.44$ \\
\hline $\begin{array}{l}\text { HK-loaded NCs (F7) } \\
\left(15 \mathrm{mg} \mathrm{kg}^{-1}\right)\end{array}$ & $\begin{array}{l}20.95 \pm \\
6.55\end{array}$ & $\begin{array}{l}42.36 \pm \\
8.68\end{array}$ & $0.48 \pm 0.99$ \\
\hline
\end{tabular}

Note: Values are represented as mean \pm SEM with $n=8$.

with HK-loaded NCs. HK-NCs successfully inhibited angiogenesis and enhanced apoptosis as assessed by tumor growth biomarkers. The PEGylated nanocapsule drug delivery system was found to be safe in vivo after systemic administration to mice-bearing tumors as indicated by immune organ index and biochemical analysis. In conclusion, our results clearly indicate that HK-loaded PEGylated NCs are a promising anticancer agent, to treat breast carcinogenesis.

\section{Disclosure}

We declare no financial or personal relationships with other people or organizations that could inappropriately affect this study. There are no competing interests in this work.

\section{References}

1. Siegel RL, Miller KD, Jemal A. Cancer statistics, 2019. CA Cancer J Clin. 2019;69(1):7-34. doi:10.3322/caac.21551

2. Nagalingam A, Arbiser JL, Bonner MY, Saxena NK, Sharma D. Honokiol activates AMP-activated protein kinase in breast cancer cells via an LKB1-dependent pathway and inhibits breast carcinogenesis. Breast Cancer Res. 2012;14(1):R35. doi:10.1186/bcr3128

3. Lee YJ, Lee YM, Lee CK, Jung JK, Han SB, Hong JT. Therapeutic applications of compounds in the Magnolia family. Pharmacol Ther. 2011;130(2):157-176. doi:10.1016/j.pharmthera.2011.01.010

4. Liou K-T, Shen Y-C, Chen C-F, Tsao C-M, Tsai S-K. The anti-inflammatory effect of honokiol on neutrophils: mechanisms in the inhibition of reactive oxygen species production. Eur J Pharmacol. 2003;475(1-3):19-27. doi:10.1016/S0014-2999(03)02121-6

5. Lo Y-C, Che-ming T, Chieh-fu C, Chien-chih C, Chuang-ye H. Magnolol and honokiol isolated from Magnolia officinalis protect rat heart mitochondria against lipid peroxidation. Biochem Pharmacol. 1994;47 (3):549-553. doi:10.1016/0006-2952(94)90187-2

6. Liou K-T, Lin S-M, Huang -S-S, Chih C-L, Tsai S-K. Honokiol ameliorates cerebral infarction from ischemia-reperfusion injury in rats. Planta Med. 2003;69(2):130-134. doi:10.1055/s-2003-37707

7. Maruyama Y, Kuribara H. Overview of the pharmacological features of honokiol. CNS Drug Rev. 2000;6(1):35-44. doi:10.1111/j.15273458.2000.tb00136.x 
8. Atanasov AG, Wang JN, Gu SP, et al. Honokiol: a non-adipogenic PPAR $\gamma$ agonist from nature. Biochim Biophys Acta. 2013;1830 (10):4813-4819. doi:10.1016/j.bbagen.2013.06.021

9. Natarajan JV, Nugraha C, Ng XW, Venkatraman S. Sustained-release from nanocarriers: a review. J Control Release. 2014;193:122-138. doi:10.1016/j.jconrel.2014.05.029

10. Haggag Y, Abdel-wahab Y, Ojo O, et al. Preparation and in vivo evaluation of insulin-loaded biodegradable nanoparticles prepared from diblock copolymers of PLGA and PEG. Int $J$ Pharm. 2016;499(1-2):236-246. doi:10.1016/j.ijpharm.2015.12.063

11. Haggag YA, Matchett KB, Dakir El H, et al. Nano-encapsulation of a novel anti-Ran-GTPase peptide for blockade of regulator of chromosome condensation 1 (RCC1) function in MDA-MB-231 breast cancer cells. Int J Pharm. 2017;521(1-2):40-53. doi:10.1016/j.ijpharm.2017.02.006

12. Haggag YA, Osman MA, El-gizawy SA, et al. Polymeric nano-encapsulation of 5-fluorouracil enhances anti-cancer activity and ameliorates side effects in solid Ehrlich Carcinoma-bearing mice. Biomed Pharmacother. 2018;105:215-224. doi:10.1016/j. biopha.2018.05.124

13. Drozdek S, Bazylińska U. Biocompatible oil core nanocapsules as potential co-carriers of paclitaxel and fluorescent markers: preparation, characterization, and bioimaging. Colloid Polym Sci. 2016;294:225-237. doi:10.1007/s00396-015-3767-5

14. Klippstein R, Wang JT, El-gogary RI, et al. Passively targeted curcumin-loaded PEGylated PLGA nanocapsules for colon cancer therapy in vivo. Small. 2015;11(36):4704-4722. doi:10.1002/ smll.201403799

15. Szczepanowicz K, Bazylinska U, Pietkiewicz J, Szyk-warszynska L, Wilk KA, Warszynski P. Biocompatible long-sustained release oil-core polyelectrolyte nanocarriers: from controlling physical state and stability to biological impact. Adv Colloid Interface Sci. 2015;222:678-691. doi:10.1016/j.cis.2014.10.005

16. Bazylińska U, Lewińska A, Lamch Ł, Wilk KA. Polymeric nanocapsules and nanospheres for encapsulation and long sustained release of hydrophobic cyanine-type photosensitizer. Colloids Surf a Physicochem Eng Asp. 2014;442:42-49. doi:10.1016/j.colsurfa. 2013.02 .023

17. $\mathrm{Hu} \mathrm{C}$, Chen $\mathrm{Z}, \mathrm{Wu} \mathrm{S}$, et al. Micelle or polymersome formation by PCL-PEG-PCL copolymers as drug delivery systems. Chin Chem Lett. 2017;28(9):1905-1909. doi:10.1016/j.cclet.2017.07.020

18. Haggag YA, Faheem AM, Tambuwala MM, et al. Effect of poly (ethylene glycol) content and formulation parameters on particulate properties and intraperitoneal delivery of insulin from PLGA nanoparticles prepared using the double-emulsion evaporation procedure. Pharm Dev Technol. 2018;23(4):370-381. doi:10.1080/ 10837450.2017.1295066

19. Haggag YA, Faheem AM. Evaluation of nano spray drying as a method for drying and formulation of therapeutic peptides and proteins. Front Pharmacol. 2015;6:140. doi:10.3389/ fphar.2015.00140

20. Haggag YA, Matchett KB, Falconer RA, et al. Novel ran-RCC1 inhibitory peptide-loaded nanoparticles have anti-cancer efficacy in vitro and in vivo. Cancers. 2019;11(2):222. doi:10.3390/ cancers 11020222

21. Han M, Yu X, Guo Y, Wang Y, Kuang H, Wang X. Honokiol nanosuspensions: preparation, increased oral bioavailability and dramatically enhanced biodistribution in the cardio-cerebro-vascular system. Colloids Surf B Biointerfaces. 2014;116:114-120. doi:10.1016/j.colsurfb.2013.12.056

22. Zheng X, Kan B, Gou M, et al. Preparation of MPEG-PLA nanoparticle for honokiol delivery in vitro. Int J Pharm. 2010;386(1-2):262-267. doi:10.1016/j.ijpharm.2009.11.014

23. Tang P, Sun Q, Yang H, Tang B, Pu H, Li H. Honokiol nanoparticles based on epigallocatechin gallate functionalized chitin to enhance therapeutic effects against liver cancer. Int J Pharm. 2018;545 (1):74-83. doi:10.1016/j.ijpharm.2018.04.060
24. Wu W, Wang L, Wang L, et al. Preparation of honokiol nanoparticles by liquid antisolvent precipitation technique, characterization, pharmacokinetics, and evaluation of inhibitory effect on HepG2 cells. Int $J$ Nanomedicine. 2018;13:5469-5483. doi: 10.2147/IJN.S178416

25. Wu Q, Zhang M, Luo H, Yi T. Self-assembled honokiol-loaded microbubbles in the treatment of ovarian cancer by ultrasound irradiation. J Biomed Nanotechnol. 2018;14(10):1796-1805. doi:10.1166/jbn.2018.2628

26. Wang X-H, Cai -L-L, Zhang X-Y, et al. Improved solubility and pharmacokinetics of PEGylated liposomal honokiol and human plasma protein binding ability of honokiol. Int J Pharm. 2011;410 (1):169-174. doi:10.1016/j.ijpharm.2011.03.003

27. Gou M, Zheng X, Men K, et al. Self-assembled hydrophobic honokiol loaded MPEG-PCL diblock copolymer micelles. Pharm Res. 2009;26(9):2164-2173. doi:10.1007/s11095-009-9929-8

28. Qiu N, Cai LL, Xie D, et al. Synthesis, structural and in vitro studies of well-dispersed monomethoxy-poly(ethylene glycol)-honokiol conjugate micelles. Biomed Mater. 2010;5(6):065006. doi:10.1088/17486041/5/6/065006

29. AbdElhamid AS, Zayed DG, Helmy MW, et al. Lactoferrin-tagged quantum dots-based theranostic nanocapsules for combined COX-2 inhibitor/herbal therapy of breast cancer. Nanomedicine (Lond). 2018;13(20):2637-2656. doi:10.2217/nnm-2018-0196

30. Abdelmoneem MA, Elnaggar MA, Hammady RS, et al. Dualtargeted lactoferrin shell-oily core nanocapsules for synergistic targeted/herbal therapy of hepatocellular carcinoma. ACS Appl Mater Interfaces. 2019;11(30):26731-26744. doi:10.1021/acsami.9b10164

31. Fessi H, Puisieux F, Devissaguet JP, Ammoury N, Benita S. Nanocapsule formation by interfacial polymer deposition following solvent displacement. Int J Pharm. 1989;55(1):R1-R4. doi:10.1016/ 0378-5173(89)90281-0

32. Ahmed O, Ahmed R. Anti-proliferative and apoptotic efficacies of ulvan polysaccharides against different types of carcinoma cells in vitro and in vivo. $J$ Cancer Sci Ther. 2014;6:202-208. doi:10.4172/1948-5956.1000272

33. Ahmed OM, Ahmed RR. Anti-proliferative and apoptotic efficacy of diallyl disulfide on Ehrlich ascites carcinoma. Hepatoma Res. 2015;1 (2):67-74. doi:10.4103/2394-5079.157602

34. Papadopoulos D, Kimler BF, Estes NC, Durham FJ. Growth delay effect of combined interstitial hyperthermia and brachytherapy in a rat solid tumor model. Anticancer Res. 1989;9(1):45-47.

35. BassiouniSanceau J, Poupon MF, Delattre O, Sastre-garau X, Wietzerbin J. Strong inhibition of Ewing tumor xenograft growth by combination of human interferon-alpha or interferon-beta with ifosfamide. Oncogene. 2002;21(50):7700-7709. doi:10.1038/sj.onc.1205881

36. Mora-huertas CE, Fessi H, Elaissari A. Polymer-based nanocapsules for drug delivery. Int J Pharm. 2010;385(1-2):113-142.

37. Zhang J, Jiang W, Zhao X, Wang Y. Preparation and characterization of polymeric micelles from poly (d, 1-lactide) and methoxypolyethylene glycol block copolymers as potential drug carriers. Tsinghua Sci Technol. 2007;12(4):493-496. doi:10.1016/S1007-0214(07)70073-1

38. Essa S, Rabanel JM, Hildgen P. Effect of polyethylene glycol (PEG) chain organization on the physicochemical properties of poly $(\mathrm{D}$, L-lactide) (PLA) based nanoparticles. Eur J Pharm Biopharm. 2010;75(2):96-106. doi:10.1016/j.ejpb.2010.03.002

39. Khan MN, Haggag YA, Lane ME, McCarron PA, Tambuwala MM. Polymeric nano-encapsulation of curcumin enhances its anti-cancer activity in breast (MDA-MB231) and lung (A549) cancer cells through reduction in expression of HIF-1alpha and nuclear p65 (Rel A). Curr Drug Deliv. 2018;15(2):286-295. doi:10.2174/ 1567201814666171019104002

40. El-hammadi MM, Delgado AV, Melguizo C, Prados JC, Arias JL. Folic acid-decorated and PEGylated PLGA nanoparticles for improving the antitumour activity of 5-fluorouracil. Int J Pharm. 2017;516 (1-2):61-70. doi:10.1016/j.ijpharm.2016.11.012 
41. Locatelli E, Comes Franchini M. Biodegradable PLGA-b-PEG polymeric nanoparticles: synthesis, properties, and nanomedical applications as drug delivery system. J Nanopart Res. 2012;14(12):1-17. doi: 10.1007/s11051-012-1316-4

42. Balakumar K, Raghavan CV, Selvan NT, Prasad RH, Abdu S. Self nanoemulsifying drug delivery system (SNEDDS) of rosuvastatin calcium: design, formulation, bioavailability and pharmacokinetic evaluation. Colloids Surf B Biointerfaces. 2013;112:337-343. doi:10.1016/j.colsurfb.2013.08.025

43. Avgoustakis K, Beletsi A, Panagi Z, et al. Effect of copolymer composition on the physicochemical characteristics, in vitro stability, and biodistribution of PLGA-mPEG nanoparticles. Int J Pharm. 2003;259(1-2):115-127. doi:10.1016/S0378-5173(03)00224-2

44. Pamujula S, Hazari S, Bolden G, et al. Cellular delivery of PEGylated PLGA nanoparticles. J Pharm Pharmacol. 2012;64 (1):61-67. doi:10.1111/j.2042-7158.2011.01376.x

45. Silva LA, Nascimento KA, Maciel MC, et al. Sunflower seed oil-enriched product can inhibit Ehrlich solid tumor growth in mice. Chemotherapy. 2006;52(2):91-94. doi:10.1159/000091308

46. Sakai M, Ferraz-de-paula V, Pinheiro ML, et al. Translocator protein $(18 \mathrm{kDa})$ mediates the pro-growth effects of diazepam on Ehrlich tumor cells in vivo. Eur J Pharmacol. 2010;626(2-3):131-138. doi:10.1016/j.ejphar.2009.09.036

47. Bai X, Cerimele F, Ushio-fukai M, et al. Honokiol, a small molecular weight natural product, inhibits angiogenesis in vitro and tumor growth in vivo. $J$ Biol Chem. 2003;278(37):35501-35507. doi:10.1074/jbc.M302967200
48. Wong RSY. Apoptosis in cancer: from pathogenesis to treatment. J Exp Clin Cancer Res. 2011;30(1):87. doi:10.1186/1756-9966-30-87

49. Wieck MM, Spurrier RG, Levin DE, et al. Sequestration of vascular endothelial growth factor (VEGF) induces late restrictive lung disease. PLoS One. 2016;11(2):e0148323. doi:10.1371/journal. pone. 0148323

50. Wang C, Youle RJ. The role of mitochondria in apoptosis. Annu Rev Genet. 2009;43:95-118. doi:10.1146/annurev-genet-102108-134850

51. O'donovan N, Crown J, Stunell H, et al. Caspase 3 in breast cancer. Clin Cancer Res. 2003;9(2):738-742.

52. Chio CC, Chen KY, Chang CK, et al. Improved effects of honokiol on temozolomide-induced autophagy and apoptosis of drug-sensitive and -tolerant glioma cells. BMC Cancer. 2018;18(1):379. doi:10.1186/s12885-018-4267-z

53. Huang K, Chen Y, Zhang R, et al. Honokiol induces apoptosis and autophagy via the ROS/ERK1/2 signaling pathway in human osteosarcoma cells in vitro and in vivo. Cell Death Dis. 2018;9(2):157. doi:10.1038/s41419-017-0166-5

54. Chilampalli S, Zhang X, Fahmy H, et al. Chemopreventive effects of honokiol on UVB-induced skin cancer development. Anticancer Res. 2010;30(3):777-783.

55. van Vlerken LE, Vyas TK, Amiji MM. Poly(ethylene glycol)-modified nanocarriers for tumor-targeted and intracellular delivery. Pharm Res. 2007;24(8):1405-1414. doi:10.1007/s11095007-9284-6
International Journal of Nanomedicine

\section{Publish your work in this journal}

The International Journal of Nanomedicine is an international, peerreviewed journal focusing on the application of nanotechnology in diagnostics, therapeutics, and drug delivery systems throughout the biomedical field. This journal is indexed on PubMed Central, MedLine, CAS, SciSearch ${ }^{\circledR}$, Current Contents ${ }^{\mathbb{R}} /$ Clinical Medicine, $^{-}$

\section{Dovepress}

Journal Citation Reports/Science Edition, EMBase, Scopus and the Elsevier Bibliographic databases. The manuscript management system is completely online and includes a very quick and fair peer-review system, which is all easy to use. Visit http://www.dovepress.com/ testimonials.php to read real quotes from published authors. 